九州大学学術情報リポジトリ

Kyushu University Institutional Repository

\title{
The Family Curculionidae of Japan. VIII.
}

\section{Subfamily Acicnemidinae}

Morimoto, Katsura

Entomological Laboratory, Faculty of Agriculture, Kyushu University

Miyakawa, Sumiaki

Entomological Laboratory, Faculty of Agriculture, Kyushu University

https://doi.org/10.5109/2581

出版情報: ESAKIA. 35, pp. 17-62, 1995-01-31. Entomological Laboratory, Faculty of Agriculture， Kyushu University

バージョン：

権利関係: 


\title{
The Family Curculionidae of Japan. VIII. Subfamily Acicnemidinae1)
}

\author{
Katsura Morimoto \\ Entomological Laboratory, Faculty of Agriculture, \\ Kyushu University, Fukuoka, 812 Japan \\ and \\ Sumiaki MiYAKAwA \\ 15-6, Hyakunin-cho 2-chome, Shinjuku-ku, \\ Tokyo, 169 Japan
}

\begin{abstract}
A bstract. Japanese species of the subfamily Acicnemidinae are systematically revised treating 23 species and a subspecies in $\mathbf{3}$ genera, of which 11 species and a subspecies are new to science and two species are new to the fauna of Japan. Atrachodes Morimoto is newly synonymized with Trachodes Germar. New species are: Trachodes ovipennis sp. nov., Trachodes monticola sp. nov., Trachodes simulator sp. nov., Trachodes sasajii sp. nov., Acicnemis nohirai sp. nov., Acicnemis dividicincta sp. nov., Acicnemis dividicincta okinawana subsp. nov., Acicnemis yakushimana sp. nov., Acicnemis shigematsui sp. nov., Acicnemis Euteomaculata sp. nov., Acicnemis azumai sp. nov. and Acicnemis exilis sp. nov. Acicnemis postica Hubenthal and sauteri Hubenthal are recorded from Japan for the first time. Keys to genera and species, descriptions of each genera and species, photographs and line drawings of important characters are provided.
\end{abstract}

Weevils of the subfamily Acicnemidinae have often confused taxonomists, especially of the apterous genera with those of the Plinthini, Anchonini and Ithyporini, and diagnostic and phylogenetic interpretations of these taxa have keenly been felt in the course the systematic study of the Cryptorhynchinae by the senior author. Present paper treats the genera and species of the Acicnemidinae of Japan as a part of our studies on the mentioned taxa in Asia.

1) Contribution from the Entomological Laboratory, Faculty of Agriculture, Kyushu University, Fukuoka (Ser. 4, No. 78). 
As defined by Zimmerman (1967), the Acicnemidinae are predominant in the Oriental Region, and Trachodes is the only genus occurring in the Palearctic and Oriental Regions. This subfamily comprises 6 genera and 212 species on record.

Semelima Pascoe (1872) was established on triangulum Pascoe and synonymized with Acicnemis by Hubenthal (1917). But, A. triangulum in his monograph was misidentified A. peduncularis Pascoe according to Marshall (1930), and the type-specimen of A. triangulum in the Natural History Museum in London is characteristic among the weevils of Acicnemis by the absence of the scutellum. This supports the resurrection of Semefimu as an independent genus.

Acicnemidiu Hubenthal (1922) was established on longimana Hubenthal as a subgenus of Acicnemis. But, it is better to treat as a full genus because of the following characteristics: antennae with seventh segment of funicle and club slender, cylindrical, almost of the same length and width to each other and similarly pubescent; prothorax with postocular lobes very weak and indefinite; and fore legs longer than the posteriors, whereas in Acicnemis hind legs are the longest.

Atruchodes Morimoto is newly synonymized with Truchodes Germar.

Ancylocnemis Marshall (1920) and its synonymic genus Epimerogryphus Heller (1922) were originally described both in the Anthonominae and were transferred to the Trachodinae by Marshall (1946). But, these weevils must be excluded from the Acicnemidinae on the following characteristics: tibiae not uncinate from the external corners, fore coxae connate, and claws toothed. Voss (1962) proposed a tribe Ancylocnemini for it near Rhynchaenini.

In consequence, five genera are recognized in the Acicnemidinae: Acicnemis, Acicnemidiu, Semelimu, Truchodes (= Atruchodes) and Karekizo, of which three genera'occur in Japan.

The length excluding rostrum in this paper denotes the distance between the apex of elytra and the base of rostrum, and the length of the elytra means the combined length of the scutellum and the suture of elytra seen dorsally. The length and width of antennal segments are measured under 210 times magnification and 100 in the description of antenna is equivalent to $0.7 \mathrm{~mm}$.

\section{Subfamily Acicnemidinae}

See Zimmerman (1967) for synonymy and discussion

Rostrum directing anteroventrally, not received on prosternum, subcylindrical, more or less dilated basally, scaled and keeled behind antennal socket, almost bare and simply punctate in male or at most finely punctate beyond them in female, epistomal margin broadly concave; mandibles prominent and meet on the median line when closed, not decussate, with two teeth on dorsal margin; eyes not prominent from head; antennal scrobes rapidly running downwards and coalescent basad on the undersurface, its dorsal margin produced ventrad in a weak curve and concealing posterior part of scrobe in lateral aspect; antennae inserted between one-fourth from the base and a little beyond the middle, scape shorter than funicle, clavate, distant from eye when rested, funicle 7-segmented, first segment robust, second segment slender, third to sixth segments short, 7th segments various, often much larger than preceding, club compact, onesegmented in general or trace of segments perceptible by the different texture of pubescene under a certain light, but sutures always obsolete in any cases in close examination. Prothorax 
with ocular lobes distinct or indefinite. Scutellum evident, small or concealed. Elytra conjointly rounded apically or shortly notched at apex of suture, ultimate stria obsolete behind metaxoca. Prosternum not sulcate for receiving rostrum, fore coxal cavities narrowly but completely separated internally and externally; middle coxal cavities also completely separated internally and externally; mesepimera produced shortly over hind margin of prothorax at anterodorsal corner and scaly fringe along dorsal margin also covers the lateral margin of elytron at base, the latter scales visible in dorsal view between hind corners of pronotum and shoulders of elytra; venter with first and second ventrites of the same length, combined length of third and fourth ventrites shorter than second. Legs long, femora more or less clavate, toothed at least on fore femora; tibiae flat, often costate at inner margin, uncinate at outer corner; tarsi with third segment much broader than second; claws simple, free. Male aedeagus with long struts, internal sac long, eighth sternite complete or separated, ninth sternite quadrangular or subcordiform, spiculum gastrale robust, curved dorsally near apex at right side of penis; tegmen with short and broad manubrium, parameres absent. Ovipositor with styli, spiculum ventrale of eighth stemite straight, long.

This subfamily is characteristic in the mandibles, antennae, antennal scrobs, mesepimera, unci of tibiae, and complete separation of fore and middle pairs of coxal cavitries. The straight posterior margin of labrum is characteristic to the larvae of this subfamily, whereas it extends medially into clypeal zone in the related subfamilies.

\section{Key to genera occurring in Japan}

1(2) Hind femora greater than fore and middle pairs, with triangular larger tooth, outer margin of tooth knife-edged to subapical constriction; tarsi with third segment deeply emarginate and bilobate; hind wings of normal size; male aedeagus with tegmen broadly open dorsally; eighth sternite of male abdomen complete, not divided

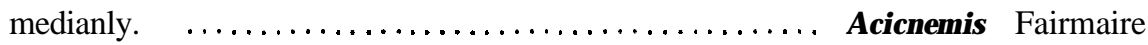

2( 1) Hind femora almost as large as or smaller than fore pair; middle and hind femora with teeth smaller than those on fore femora or vestigial; tarsi with third segment truncate or shallowly concave at apical margin; antennal funicle robust, with seventh segment transverse, much broader than sixth; male aedeagus with tegmen ringed.

3(4) Scutellum of normal size, as broad as first interval at base, scaled; elytra parallel-sided, with rectangular humeri; pronotum with three longitudinal shallow depression, obtusely edged at side margins in entire length; eighth stemite of male abdomen not divided.

$$
\text { ................. Karekizo Morimoto }
$$

4(3) Scutellum minute or concealed; elytra ovate; hind wings atrophied; pronotum evenly rounded dorsoventrally or indefinitely edged behind the middle at sides; eighth stemite of male abdomen divided by median membranous area. 


\section{Trachodes Germar}

Trachodes Germar, 1824, Ins. Sp. Nov.: 325. - Schoenherr, 1826, Curc. Disp. Meth.: 260 (designated Curculio hispidus Linnaeus as type-species).

Metrachodes Marshall, 1948, Novit. Zool., 42: 427 (Type-species: Trachodes hispidus Linnaeus by original designation). (Synonymized with Trachodes by Marshall in a foot-note on the same page). - Morimoto, 1962, J. Fac. Agr., Kyushu Univ. 12: 61.

Atrachodes Morimoto, 1962, J. Fac. Agr., Kyushu Univ., 11: 405 (Type-species: Atrachodes murakamii Morimoto, 1962, by original designation). - Morimoto, 1962, J. Fac. Agr., Kyushu Univ., 12: 61. - Morimoto, 1984, Coleopt. Jpn in col., IV: 325. syn. nov.

See Schenkling \& Marshall (1937) and Zimmerman (1967) for synonymy.

In comparison with the detailed redescription of Trachodes hispidus by Zimmerman (1967), Japanese species are different in the following points as mentioned in the key and perhaps belong to different lineage from it. The species now assigned in this genus need revision for their generic position because they are possibly a mere assemblage of apterous species. Semelima Pascoe is similar to this genus on the absense of the scutellum and moniliform funicle of antennae, but the hind femora are much longer, exceeding posteriorly beyond apex of elytra. Atrachodes is newly synonymized with it because of the discovery of additional species with intermediate characters.

Weevils of this genus are often difficult to identify owing to the loss of scaly patches and tufts by discolor, falling-off or greazing.

\section{Key to species of the genus Truchodes from Japan}

1(2) Antennae with third to fourth segments of funicle as long as or slightly longer than broad, seventh segment about as long as broad; hind tibiae strongly dilated internally beyond the middle; metepisternal sutures incomplete, only discernible before the middle; male aedeagus with tegmen incomplete, open dorsally, penis parallel-sided with subtriangular apex; eighth stemite of male abdomen undivided. (Europe). $\quad . \ldots \ldots \ldots \ldots \ldots \ldots \ldots \ldots$ [Trachodes hispidus (Linnaeus, 1758)]

2(1) Antennae with third to sixth segments of funicle broader than long, scaled, seventh segment much broader than preceding, setose; metepisternal sutures complete, discernible in entire length; male aedeagus with tegmen completely ringed, penis parallel-sided, subtruncate at apex with rounded comers; eighth sternite of male abdomen divided medianly by membranous area.

3(6) Each femur with sharp tooth, often median and hind ones smaller; tarsi with first segment slightly longer than second and third combined; male aedeagus with ostium of penis as widely distant from apex as width of penis.

4(5) Elytra ovate, 1.1-1.2 times as long as maximum width, pronotum rounded laterally and rapidly narrowed to subapical constriction from the middle; ground and suberect scales concolorous ochreous behind postmedian band, blackish tufts on third and fifth intervals conspicuous; body length $3.7-4.4 \mathrm{~mm}$.

Trachodes ovipennis sp. nov. 
5(4) Elytra oblong-ovate, 1.3 times as long as maximum width, pronotum weakly rounded laterally and weakly narrowed to subapical constriction; suberect scales on declivity of elytra ochreous, dark brownish and blackish, ground scaling predominantly dark brownish behind postmedian band, blackish tufts usually much smaller and inconspicuous on fiftrh interval than those on third interval; body length 3.2-4.4 mm. .......................... Trachodes subfasciatus Voss

6(3) Fore femora with obtuse small tooth, these of middle and hind femora vestigial or minute; tarsi with first segment as long as second and third combined; postmedian greyish band on elytra transverse with weakly arched posteriorly; male aedeagus with ostium of penis close to apex. (Atrachodes auct.)

7(10) Elytra ovate, broadest behind the middle, with evenly curved greyish band behind the middle, third interval with five scaly tufts, basal and last tufts often indistinct, second, third and fourth equidistant; 2.6-3.0 mm in length.

8(9) Elytra with blackish to brownish black tufts on weak pustules; penis weakly dilated apically, internal sac without spiny asperate area in the middle.

......... Trachodes murakamii (Morimoto)

9(8) Elytra with scaly tufts bicolorous, not born on pustules, second and fourth tufts on third interval brownish grey to whitish, the latter on greyish band, the other tufts blackish to blackish brown; penis with internal sac spiny asperate area in the middle and dense asperate area near base. ............... Trachodes sasajii sp. nov.

1O(7) Elytra oblong-ovate, with parallel-sided median area, postmedian greyish band oblique from the middle of seventh interval inwards, shortly produced posteriorly on third interval as far as fourth tuft of the pale color; penis parallel-sided.

11(12) Elytra with conjoint postmedian band W-shaped, pointed posteriorly on third interval, third tuft on third interval black and close to greyish fourth than to second; penis with internal sac densely asperate near base and simple in median area.

............. Trachodes monticola sp. nov.

12(11) Elytra with postmedian band oblique and smooth at fore margin and shortly pointed posteriorly on third interval; internal sac of penis with a pair of dense robust spiny asperities at the middle, fine spiny asperate area between them and ostium and dense asperate area near base. .................. Trachodes simulator sp. nov.

\section{Trachodes subfasciatus Voss}

(Figs. 1, 33-44)

Trachodes subfasciatus Voss, 1957, Entomol. Rev. Japan, VIII: 36 (Hoki-Daisen). - Morimoto, 1984, Coleopt. Japan in col., IV: 325, pl. 64, fig. 1 (Honshu, Shikoku, Kyushu). Morimoto and Miyakawa, 1985, Mushi, 50: 29 (Izu Isls.).

Metrachodes subfasciatus: Morimoto, 1962, Sci. Bull. Fac. Agr., Kyushu Univ., 19: 353 (Honshu, Shikoku, Kyushu) . - Nakane, 1963, Icon. Ins. Jpn col. nat ed., II. Coleopt.: 369, pl. 185, fig. 1.

Derm black, except for reddish brown apical half of rostrum, antennae, tarsi and both ends of tibiae; scaling dense, rostrum behind antennal insertions, head, prothorax at sides, lateral area of meso- and metathoraces and humeral patches brownish grey or ochreous, underside and patches on legs greyish; frons and base of rostrum with a row of brownish to brownish grey suberect 
scales on each side; pronotum with a pair of brownish scaly tufts behind apical margin, with a transverse row of four tufts of erect scales at a little in front of the middle, of which the median pair blackish and large, with a subquadrate large black basal patch at the middle; elytra with short ochreous stripe at the base of fifth interval, often with humeral patch of the same color, postmedian brownish grey band between sixth intervals almost transverse, with short indent on first interval posteriorly, alternate intervals each with a row of scattered suberect scales, blackish on dark area and greyish on postmedian band and in lateral and apical areas, third interval with three tufts of black scales, third tuft behind postmedian band often indefinite; fifth interval with two tufts of a few black scales; ground scaling of legs as in fig.44, with recumbent scattered scales greyish except for some dark ones on dark areas.

Rostrum curved. parallel-sided from base to antennae, there slightly expanded laterally, then weakly narrowing and gradually widening again to apex, rugosely punctate behind antennal sockets. with a faint median carina, punctures confluent longitudinally and forming two irregular carinulae on each side, but these structures completely concealed by scales in fresh specimens; antennae inserted in $2 / \mathrm{S}$ (male) or 1/3 (female) of rostrum from base, funicle with second segment much shorter than first, second to sixth transverse, moniliform, scaled, seventh much broader than preceding, setose. Pronotum about as long as broad, weakly rounded laterally, broadest at about the middle, slightly narrowed basally, right angled at hind corners, hind margin weakly bisinuate, evenly and weakly convex longitudinally, highest at the middle, indefinitely depressed longitudinally on each side and in the middle in entire length, reticulate dense punctures concealed by scaling, postocular lobes well produced. Scutellum concealed. Elytra oblong-ovate, slightly curved or almost parallel-sided from rounded humeri to the middle, striae with distant large oblong punctures, which diminish behind, intervals about as broad as punctures on basal half, much broader than stria on declivity. Legs with tooth smaller on middle and hind pairs than on fore pair, tibiae slender, weakly dilated internally about the middle. Male aedeagus as figured, penis about three times as long as broad, flagellum brownish on basal half.

Length: 3.2-4.4 $\mathrm{mm}$ (excl. rostrum).

Distribution: Japan (Honshu, Shikoku, Kyushu, Izu Isls., Tsushima).

Specimensexamined: 61 exs. from Izu Isls. (Oshima, Toshima, Miyake, Hachijo), Shizuoka (Mt. Manzaburodake, Ohnabe-rindo), Ishikawa (Shiramine-son), Osaka (Mt. Iwawaki), Mie (Hirakura), Nara (Mt. Koya), Hyogo (Mt. Mayasan), Okayama (Mt. Ohsayama), Shimane (Mt. Aono). Tokushima (Mt. Tsurugi. Jinryo-son), Ehime (Rakando cave), Kochi(Monobe-mura, Mt. Tebako. Tosayamada), Fukuoka (Mt. Hikosan, Mt. Kumado), Nagasaki (Mt. Iwayasan), Kumamoto (Naidaijin), Oita (Mt. Kurodake, Kyusuikei, Fukakusa, Kuju), Miyazaki (Mt. Ohkue), and Tsushima (Uchiyama-toge, Mt. Mitake).

Biological note: Weevils were captured on dead trunks and branches of the broad-leaved trees, and often collected by sifting litter of the forest floor.

\section{Trachodes ovipennis sp. nov.}

(Figs. 2, 45, 46)

Close to the preceding, but the pronotum and elytra are more strongly rounded laterally and convex dorsally, the blackish scaly tufts on pronotum and elytra are more conspicuous, and the 
elytra are ochreous on declivity.

Derm black, except for reddish brown apical half of rostrum, antennae, fifth segment of tarsi, claws, and apex of tibiae; scaling dense, overlapped each other on the base of rostrum, head, prothorax, elytra and legs, narrowly separated on the underside; greyish brown to ochreous on the base of rostrum, head, lateral area of prothorax, humeri between fifth and ninth intervals, and apical area of elytra behind postmedian band, humeral patches often interrupted by ochreous sixth interval, pronotum with large median black patch, which widening posteriorly from apical margin to $1 / 3$ from base, then narrowing posteriorly, of which outer margins parallel to side margins of pronotum and continuous to humeral patches of elytra, the remaining area of elytra almost blackish, underside with brownish grey scales; forehead between eyes with several erect scales on each side; pronotum with a transverse row of four scaly tufts at a little in front of the middle and two similar tufts on the apical margin, median pair black, large and conspicuous, the other four brownish and formed of a few scales, often indefinite; elytra with subbasal and median black tufts on third interval and two similar but smaller black tufts on fifth interval, postmedian band between fifth striae greyish, almost straight at posterior margin, slightly biarcuate at anterior margin, alternate intervals with scattered suberect scales of the same colour as to the ground scales, except for one or two black scales just behind postmedian band in some cases, legs sparsely with recumbent greyish hairy scales.

Rostrum and antennae almost the same as in T.subfasciatus. Pronotum also similar to $T$. subfasciatus, but broadest in front of the middle, more strongly rounded laterally and shortly parallel-sided at base. Elytra ovate, 1.1-I.2 times as long as maximum width, evenly curved from humeri to subapical calli at sides, striae with distant small punctures, which diminish behind, intervals much broader than striae. Legs almost the same as in T. subfasciatus, but blackish areas a little broader in general. Male aedeagus with penis about twice as long as broad, flagellum not pigmented.

Length: $3.7-4.4 \mathrm{~mm}$ (excl. rostrum).

Distribution: Japan (Honshu, Kyushu).

Holotype: male (Type No. 2952, Kyushu Univ.), Ohdaigahara, Nara Pref., 21 .vii.1992, H. Kojima leg.

Paratypes: 2 males, sama data as holotype; I male, same locality as holotype, 28-29.v.1977, K. Mizuno leg.; I male and 1 female, Mt. Manzaburodake, Izu, Shizuoka Pref., 19.v.1 980, J. Okuma leg.; 1 female, Mt. Daigatake (alt. 750m), Hakone, Kanagawa Pref., 18.vi.1978, S. Miyakawa leg.

\section{Trachodes murakamii (Morimoto, 1962), comb. nov.}

(Figs. 3, 47-57)

Atrachodes murakamii Morimoto, 1962, J. Fac. Agr., Kyushu Univ., 11: 406, fig. XIII (Mt. Hakusan).

Derm dark reddish brown, rostrum, antennae and legs reddish brown; scaling dense, rostrum behind antennal insertions. head prothorax at sides, humeral patches and apical area of elytra behind postmedian band brownish grey, postmedian band and underside greyish, pronotum with a large median black patch, which becoming brownish anteriorly before the middle, elytra variegated with blackish, dark brownish and brownish scales on the areas other than greyish 
areas; forehead with a row of erect scales on each side along inner margin of eye, pronotum with a transverse row of four fascicles at a little in front of the middle, median pair blackish and large, lateral pair brownish grey and often indefinite, a pair of brownish tufts at anterior margin, which often mixed with black scales on the posterior part, elytra with five scaly tufts on third, three tufts on fifth and two fascicles on seventh interval in fresh specimens, but these variable in size and often indefinite, alternate intervals with a row of scattered suberect or recumbent scales.

Rostrum evenly curved at basal two-thirds, then almost straight to apex, behind antennae with a sharp median carina in male or fine one in female and longitudinally confluent puctures, finely punctate before antennae; antennae inserted into 1/4 of rostrum from the base, funicle scaled from first to sixth, second segment shorter than first, third to seventh segments broader than long, seventh segment much broader than preceding, setose, club short. Pronotum 1.121.24 times as broad as long, almost parallel-sided or weakly curved on basal half, slightly depressed longitudinally exterior to front of third interval along side margins as far as subapical transverse weak depression. Scutellum minute, bare. Elytra ovate, broadest at or alittle behind the middle, about 1.2 times as long as broad, evenly rounded at sides from rectangular humeri to subapical swellings, evenly convex dorsally, highest at the middle, striae, narrow, separately punctate, septa of them much shorter than their diameter, which diminish behind, intervals dilated laterally and weakly pustulate at scaly tufts. Legs with fore femora bluntly toothed, middle and hind femora unarmed or with minute denticle. Fifth ventrite semicircularly depressed at apex in male. Male aedeagus slightly widening apically, internal sac with a pair of asperate areas.

Length: 2.3-3.0 mm (excl. rostrum).

Distribution: Japan (Honshu).

Specimens examined: Mt. Shirakamidake, Iwasaki-mura, Aomori Pref., 1 male, 27.vii.1993, S. Yamauchi leg. Rokumai (Senboku toge), Akita Pref., 1 female, 22.vi.1975, S. Miyakawa leg. Ohataki-rindo, Fujisato-cho, Akita Pref., 1 female, 27.vii.1991, E. Terasawa leg. Mt. Hakusan, Ishikawa Pref., 1 female, 31.vii.1956, Y. Murakami leg.(Holotype); 1 female, (2000 m alt.), 27.vii.1982, I. Togashi leg.; 3 males and 3 females, (1310, 1550 \& $1600 \mathrm{~m}$ alt.), 4.vii.1993, K. Nakata leg.; 1 female, 28.viii.1993, K. Nakata leg. Shirakitoge, Shiramine-son, Ishikawa Pref., 1 male, 20.viii.1993, K. Nakata leg. Yashagaike, Fukui Pref., 4 males, 9.viii.1990, S. Nomura leg. Takeda, Fukui Pref., 1 female, 1.vii.1973, H. Sasaji leg. Taniyama, Ohno City, Fukui Pref., 1 female, 24.vi.1982, K. Morimoto leg.

Note: This species was described on one female and has been confused with next species. Weevils were often captured by sifting litter.

\section{Trachodes sasajii sp. nov.}

(Figs. 4, 58-61)

Atrachodes murakamii: Nakane (nec Morimoto), 1963, Icon. Ins. Jpn. col. nat. ed., II: 369, pl. 185, fig. 3. - Morimoto, 1984, Coleopt. Jpn in col., IV: 325, pl. 64, fig. 4.

Very close to T.murakamii and variable, but elytra are a little longer, less rounded laterally and the second scaly tuft on third interval of elytra brownish.

Scaly tufts of elytra bicolorous, second and fourth tufts on third interval brownish grey to whitish, the latter on greyish postmedian band, the other tufts blackish to blackish brown, often 
with a trace of greyish band parallel to postmedian band along anterior margins of third tuft on third interval and second tuft on fifth interval. Pronotum about as long as broad, almost parallelsided or broadest at or behind the middle, then slightly narrowed posteriorly. Elytra oblongovate, 1.3-1.4 times as long as broad, straight and weakly dilated to the broadest point at or a little behind the middle at sides from a point above middle coxa, intervals hardly dilated and not pustulate at scaly tufts. Penis with internal sac spiny asperate in the middle and densely asperate near the base.

Length: 2.6-3.7 $\mathrm{mm}$ (excl. rostrum).

Distribution: Japan (Honshu).

Holotype: male (Type No. 2953, Kyushu Univ.), Koike, Fukui Pref., 20-24.vii.1964, H. Sasaji leg.

Paratypes: Riv. Chiroro, Mt. Totsutabetsu, Hokkaido, 1 female, 15.vii.1976, H. Irie leg. Oirase, Aomori Pref., 2 males, 19.v.1976\& 18.vi.1977, A. Abe leg.; 1 female, 18.vi.1988, S. Yamauchi leg. Kawauchi, Shimokita-gun, Aomori Pref., 1 female, 25.vii.1984, S. Yamauchi leg. Mt. Mahiro-dake, Sawauchi v., Iwate Pref., 1 male, 3.vii.1988, Y. Takahashi leg. Takane, Niigata Pref., 1 female, 27.vii.1962, K. Baba leg. Chuzenji, Nikko, Tochigi Pref., 1 male, 17.vii.1962, Tezuka leg. Sugenuma, Gunma Pref., 1 male, 10- 11 .vii. 1973, H. Irie leg. Mt. Kisokoma, Nagano Pref., 3 males and 1 female, 28.viii.1962, K. Morimoto leg. Mugikusatoge, Tadeshinakogen, Nagano Pref., 1 female, 29.vi.1977, S. Miyakawa leg. Mt. Togasa, Izu, Shizuoka Pref., 1 male, 31 .v.1970, S. Miyakawa leg. Same data as holotype, 1 female. Kyogatake, Ohno, Katsuyama, Fukui Pref., 2 females, 27.vi.1976 \& 29.v.1982. H. Sasaji leg. Taniyama, Ohno City, Fukui Pref., 1 male, 24.vi.1982, K. Morimoto leg. Mt. Gomadan, Wakayama Pref., 1 female, 25.v. 1975, K. Masuo leg.

\section{Trachodes monticola sp. nov.}

(Figs. 5, 6, 64-71)

Similar to Truchodes sasajii, but the elytra are parallel-sided for a short distance before the middle, second scaly tuft on third interval blackish brown to black and postmedian greyish band W-shaped.

Derm dark reddish brown to reddish brown, rostrum, antennae and legs lighter: scaling dense, rostrum at base and head brownish grey except for greyish fringe along dorsal and hind margins of eyes, with a row of erect brownish setae between eyes and base of rostrum on each side; pronotum brownish grey with two greyish stripes on each side behind the middle, one at side edge and the other before fifth interval, with a large median blackish patch, with a transverse row of tufts formed of a few scales at a little in front of the midde, median ones larger and blackish, lateral ones smaller or often indefinite, brownish grey, and a pair of similar tufts of brownish to dark brown scales at anterior margin; elytra variegated with brownish, greyish and brownish black scales, brownish scales forming humeral patches exterior to fifth stria, oblique patch from eighth interval a little behind the middle to sixth interval behind postmedian band, marginal stripe on two lateral intervals and irregular patch on declivity, but two latter patches variable and often absent, usually with greyish patch at the base of fifth interval, postmedian greyish band $\mathrm{W}$-shaped between sixth intervals delicate, often diminished on fourth interval, third interval with five blackish scaly tufts, except for brownish grey fourth tuft on the point of 
greyish band and close to blackish third tuft, greyish scattered scales often forming indefinite band on basal third, alternate intervals with scattered erect blackish and greyish scales.

Rostrum curved, slightly narrowed between apex and antennal insertions, densely punctate and with a median and two weak lateral carinae at scaled area behind antenna1 sockets in male or the carinae indefinite in female, punctures diminish anteriorly in male, or fine in female; antennae inserted in 1/3 (male) or 1/4 (female) of rostrum from the base of rostrum, robust, second segment of funicle shorter than first, third to sixth segments broader than long, seventh segment much broader than preceding, club compact, ovate, with traces of two sutures under a certain light. Pronotum almost as long as broad, parallel-sided in the middle, slightly narrowed at base, a little smaller than right angle at hind corners, bisinuate at hind margin, weakly convex longitudinally and highest before the middle in lateral aspect, slightly and broadly depressed longitudinally along side margins, obtusely and indefinitely edged at sided from base to subapical constrictrion. Scutellum minute, with greyish scales. Elytra oblong-ovate, 1.451 .70 times as long at suture as broad, parallel-sided a little behind humeri to the middle, striae narrow, with distant punctures, intervals flat, tufted intervals a little broader than the others. Fore femora with small but sharp tooth, middle and hind femora unarmed. Tibiae scarcely dilated in the middle. Tarsi with first segment as long as second and third combined. Male aedeagus similar to sasajii, but median asperate area on internal sac absent.

Length: 3.4-3.9 mm (excl. rostrum).

Distribution: Japan (Honshu).

Holotype: male (Type No. 2954, Kyushu Univ.), Mt. Kisokoma, Nagano Pref., 25.viii.1962, K. Morimoto leg.

Paratypes: Same data with holotype 3 females. Same locality with holotype, 2 males, 19.vii.1962, K. Oshima leg.; 9 males and 4 females, 28.viii.1962, K. Morimoto leg. Mugikusatoge (alt. 2000m), Tadeshina-kogen, 2 females, 29.vi.1977, S. Miyakawa leg.; 1 male and 1 female, 21 .vii.1991, R. Horikawa leg. Shibunoyu, Tadeshina-kogen, Nagano Pref., 1 female, 28.vi.1977, S. Miyakawa leg. Sasagamine, Niigata Pref., 1 female, 28.viii.1952, Y. Wada leg. Sugenuma, Gunma Pref., 1 female, 10-1 1.vii.1975, H. Irie leg. Nikamatazawa, Mt.Shirane, Gunma Pref., 1 female, 16-18.vii.1975, H. Irie leg. Daibosatsu-toge, Yamanashi Pref., 1 female, 17.vi.1973, M. Ito leg.

Biological note: Weevils were captured on dead branch of Abies veitchii (Shirabiso in Japanese).

\section{Trachodes simulator sp. nov.}

(Figs. 7, 62, 63)

Very close to T. monticola in size, body shape and scaly pattern, but different from it in the following points:

Elytra with postmedian greyish band V-shaped, smoothly oblique at fore margin and shortly pointed posteriorly on third interval, scaly tufts five on third interval, black except for greyish to brownish grey fourth, which lying at the point of band and formed of two or three scales, second, third and fourth tufts equidistant, third tuft shortly distant anteriorly from band, fifth tuft usually indefinite. Internal sac of penis with a pair of dense robust spiny asperities in the middle, fine spiny area between them and ostium, and dense asperate area near base. 
Length: 3.9-4.3 mm (excl. rostrum).

Distribution: Japan (Honshu, Shikoku, Kyushu).

Holotype: male (Type No. 2955, Kyushu Univ.), Mt. Tebako, Kochi Pref., 7-10.viii.1957, K. Morimoto leg.

Paratypes: Oniwa, Mt. Fuji, Yamanashi Pref., 1 male, 22.vii.1962, K. Morimoto leg. Same data as holotype, 1 female. Mt. Sobo, Oita Pref., 2 females, 5.vii.1954, H. Kamiya leg.

\section{Karekizo Morimoto}

Karekizo Morimoto, 1962, J. Fac. Agr., Kyushu Univ., 11: 403 (Type-species: Karekizo impressicollis Morimoto, 1962, by original designation). - Morimoto, 1962, J. Fac. Agr., Kyushu Univ., 12: 61. - Morimoto, 1984, Coleopt. Jpn in col., IV: 325.

Very close to Trachodes, especially to the species group of T. sasajii, monticola and simulator, but scutellum is as broad as the base of first interval and scaled, elytra are parallelsided, hind wings are normal in size, pronotum is distinctly edged at sides in entire length, and eighth sternite of male abdomen is complete and not divided medianly by membranous part. The type-species of the genus is unarmed on the middle and hind femora, but an unnamed species from Taiwan before us has a small tooth on these femora.

\section{Karekizo impressicollis Morimoto}

(Figs. 8, 9, 72-81)

Karekizo impressicollis Morimoto, 1962, J. Fac. Agr., Kyushu Univ., 11: 404 (Mie Univ. Forest in Mie, Daisen). - Morimoto, 1984, Coleopt. Jpn in col., IV: 325, pl.64, fig.2 (Honshu, Kyushu).

Derm brown to dark brown; scaling dense, rostrum behind antennal insertion, head and prothorax greyish to brownish grey, except for subquadrate median black patch on pronotum behind the middle, humeral patch and postmedian band on elytra greyish, undersurface greyish except for brownish lateral surfaces from mesothorax to second ventrite, and median area of third and fourth ventrites often brownish; rostrum and forehead with erect brownish grey scales, pronotum with six scaly tufts, one pair on the anterior margin brownish grey and large, one pair on the sides a little before the middle brownish grey and small, median pair dark brownish grey, elytra with five tufts each on third and fifth intervals, second and fourth tufts brownish grey and the others blackish, second and third tufts on third interval large and conspicuous, the other tufts small or often indefinite, formed of a few scales, alternate intervals with scattered suberect scales brownish grey and blackish.

Rostrum curved, with median carina extending anteriorly beyond the middle in male; antennae inserted in 1/3 (male) or 1/4 (female) of rostrum from the base of rostrum, second segment of funicle a little shorter than first, third to sixth transverse, seventh much broader than preceding, club compact with traces of sutures as different texture under a certain light. Pronotum 1 1 1-1.2 times as broad as long, almost parallel-sided behind lateral scaly tuft, or broadest just before the base and slightly narrowed anteriorly to the tuft, often slightly sinuate at edged lateral margins, disk with three longitudinal depressions, one pair along side margins covered with greyish scales, median depression often weakened anteriorly. Scutellum as broad as 
first interval at base, scaled. Elytra 1.42-1 .62 times as long as broad, parallel-sided a little behind humeri to apical one-third, intervals much broader than striae, third interval weakly costate at the base, subapical calli weak, often with scaly tuft. Male aedeagus with penis parallel-sided, broadly rounded at apex, internal sac with densely asperate area at basal area and finely asperate area in the middle, eighth sternite not divided.

Length: 3.1-4.5 mm (excl. rostrum).

Distribution: Japan (Honshu, Shikoku, Kyushu).

Specimens examined: 16 specimens including holotype and paratypes from Yamanashi (Fuji-rindo), Mie (Mie Univ. Forest), Tottori (Mt. Daisen), Kochi (Mt. Tebako), Fukuoka (Mt. Kumado), and Kumamoto (Shiiya-toge) in June and July.

\section{Acicnemis Fairmaire}

Acicnemis Fairmaire, 1849, Rev. Mag. Zool., 1849: 511 (rep.: 63)(Type-species: Acicnemis variegatus Fairmaire, 1849, monobasic). - Lacordaire, 1866, Gen. Col., VII: 31. Chevrolat, 1878, Pet. nouv. Ent., $2: 203$ \& 206. - Hubenthal, 1917, Arch. f. Naturg., 83 A (8): 92-160; (9): 53-155 (=Berethia, Semelima). - Morimoto, 1962, J. Fac. Agr., Kyushu Univ., 12: 61. - Morimoto, 1984, Coleopt. Jpn in col., IV: 325.

Berethia Pascoe, 1872, J. Linn. Soc. Lond., XI: 463 (Described on Berethia medinotata Pascoe and sannio Pascoe). - Chevrolat, 1878, Pet. nouv. Ent., 2: 206. - Faust, 1898, Deut. ent. Zschr., 1898: 313, note (?=Acicnemis).

The genus Acicnemis defined by Hubenthal (1917) comprises characteristic weevils on the following points:,hind femora much greater than anterior pairs, narrowly stalked at base and clavate at apex, femoral tooth large, triangular and knife-edged at exterior margin; tibiae uncinate at outer corner; tarsi with third segment deeply bilobate; claws simple, free; prothorax with strong postocular lobes; scutellum evident; prosternum not sulcate; pro- and mesocoxae completely separated internally and externally, prosternal process linear; hind wings of normal size; eighth sternite of male abdomen complete, not divided medianly by membranous part; male aedeagus with tegmen broadly open dorsally; derm densely covered with scales; rostrum at base, head between eyes, pronotum and elytra with scaly tufts.

Japanese species are collected on dead stem and branch of broad-leaved trees and vines, and not on conifers.

\section{Key to species of the genus Acicnemis from Japan}

1(32) Hind tibiae curved at base and thence straight or slightly sinuate towards apex, more or less dilated internally at apical third or about the middle.

2(25) Antennae with fifth and sixth segments almost as long as or 0.8-1.2 times as long as broad, club without neck at base.

3(4) Hind tibiae slightly dilated internally behind the middle, inner apical corners of tibiae rounded in male; elytra without postmedian pale band, predominantly dark brownish to brownish blackish, with humeral patches and declivity greyish brown, 
and with conspicuous black stripe behind scutellum on basal third of first interval; 3.2-4.0 mm. ........................ Acicnemis suturalis Roelofs

4(3) Hind tibiae strongly dilated internally at apical third, inner apical corners of tibiae pointed or angulate in both sexes.

5(6) Elytra with first interval yellowish brown to greyish ochraceous in the middle between basal black stripe and black patch on declivity in contrast to greyish brown general scaling, postmedian patch often indefinite or slightly greyish, with V-shaped black posterior border, with short black stripes before the middle on third, fifth and seventh intervals in general, often with additional black stripes close to the base of third interval and a little behind the base of fifth interval; 3.6-4.2 mm. $\ldots \ldots \ldots \ldots \ldots \ldots$ Acicnemis azumai sp. nov.

6(5) Elytra with first interval similarly coloured to the neighbouring intervals in the middle, blackish, posterior fringe of postmedian patch either divided by suture or distant from the patch if present.

7(16) Postmedian patch not interrupted by suture.

8(9) Postmedian band of elytra whitish, M-shaped or often flat V-shaped on blackish ground scaling, with greyish stripes along side margins of pronotum, with greyish humeral and apical patches on elytra; 4.5-5.6 mm. ........... Acicnemis albofasciata (Ter-Minasyan)

9(8) Postmedian band of elytra not M-shaped, but weakly arched posteriorly, more or less thickened medianly.

10(13) Funicle with second segment shorter than first, its length almost the same as breadth of first, third to sixth segments moniliform, small species, 3.0-4.0 $\mathrm{mm}$ in length.

11(12) Postmedian white patch cordiform, not extending laterally beyond third stria and surrounded by narrow black belt, with blackish lateral stripe arising from ninth interval and transferred to eighth interval shortly behind shoulder as far as apex, another brownish black to blackish stripe from base to basal quarter of second interval, then transferred to third interval and continuously round along anterior border of cordiform patch, the remaining area of elytra greyish brown, median area between latter stripes often darker; 3.2-3.6 mm. ........ Acicnemis shibatai Voss

12(11) Postmedian greyish patch band-like, extending laterally to fifth interval, dorsal area between sixth interval before postmedian band almost blackish, with short basal velvety black stripe on first interval, the other area of elytra almost brownish grey; 3.0-4.0 mm. ....................... Acicnemis dorsonigrita Voss

13(10) Funicle with second segment slender, at least as long as first, third and fourth segments a little longer than broad and much longer than fifth; postmedian band flat $\mathrm{V}$ shaped, greyish brown, dorsal area before postmedian band almost blackish; larger species, more than $5 \mathrm{~mm}$ in length.

14(15) Postmedian band extending laterally to fourth interval, marginate posteriorly with black narrow band, suture without velvety stripe, venter brownish except for greyish median area of first and second ventrites; 6.1-6.5 mm.

................. Acicnemis shigematsui sp. nov.

15(14) Postmedian greyish band extending laterally to fifth interval, continuous to greyish brown lateral and apical areas, without black interruption, usually with velvety black 
short stripes one at base and the other in the middle on first interval, the latter continuous to anterior border of postmedian patch and anchor-shaped, venter greyish, with a dark brown patch on each side of second ventrite; 5.0-6.9 mm.

.................. Acicnemis palliata Pascoe

16(7) Postmedian patch of elytra interrupted by suture, paired.

17(24) Funicle with fourth segment slightly or scarcely shorter than third and almost as long as fifth.

18(21) Ground scaling almost concolorous, almost sooty black or sooty blackish brown, elytra with a conjoint transverse velvety black patch on declivity.

19(20) Ground scaling almost entirely sooty black, with a pair of greyish to brownish grey narrow postmedian patches, basal velvety short patch on first interval; 4.5-5.7 mm. ................ Acicnemis nohirai sp. nov.

20(19) Scaling almost sooty black with brownish tinge, postmedian patches ochreous to brownish grey, oblique, basal velvety black patch subquadrate on first and second intervals; 4.3-4.8 mm. (Taiwan). ............ [ Acicnemis nobilis Hubenthal ]

21(18) Scaling variegated with black, brown, dark brown and greyish brown scales; pronotum broadly brownish to brownish grey along side margins, velvety black patch on declivity interrupted by suture or indefinite. ...... Acicnemis dividicincta sp. nov.

22(23) Velvety black patch on declivity of elytra indefinite or absent, funicle with fourth and sixth segments as long as broad, pronotum brownish grey along side margin; 4.5$5.3 \mathrm{~mm}$; Honshu, Shikoku, Kyushu.

.... Acicnemis dividicincta dividicincta nominate subsp.

23(22) A paired velvety black patches on declivity of elytra distinct, funicle with fourth and sixth segments 1.2 times as long as broad, pronotum greyish brown, with a pair of quadrate basal black patches, greyish to whitish stripes in front of fifth interval parallel to side margin and below side margin in entire length on each side; 4.8-6.4 $\mathrm{mm}$; Amami-Oshima and Okinawa Isls.

....... Acicnemis dividicincta okinawana subsp. nov.

24(17) Funicle with third and fourth segments slender, fourth segment 1.5 times as long as broad and about 1.5 times as long as fifth, ground scaling predominantly brownish black, with a pair of greyish to brownish grey postmedian patches, velvety black patches on declivity of second to fourth intervals; 6.0-6.4 mm.

. . . ............ Acicnemis yakushimana sp. nov.

25(2) Antennae slender, fifth and sixth segments more than 1.3 times as long as broad, club with narrow neck at base; hind tibiae weakly dilated internally in or a little basal to the middle; postmedian pale patch interrupted by suture, paired; scaling variegated with greyish brown, blackish and greyish scales; even numbered intervals of elytra often with a few erect similar scales to those on odd-numbered intervals at apical area.

26(27) A paired postmedian patches rectangular to suture at posterior margin; femora with two longitudinal carinae on the outside of stalk and weakly depressed between them; 3.0-5.0 mm.. .................... Acicnemis maculaalba Roelofs

27(26) Postmedian patches oblique intero-posteriorly at posterior margin.

28(29) Antennae slender, second segment of funicle about 1.9 times as long as third and more 
than twice as long as fourth, elytra with short blackish stripe behind small brownish to yellowish brown patch at the base of third interval, of which brownish patch often indefinite and much shorter than blackish stripe, fore tibiae dilated internally just basal to the middle: large species, 4.9-7.0 $\mathrm{mm}$ in length.

................ Acicnemis kiotoensis Nakane

29(28) Antennae with second segment of funicle 1.4-1.5 times as long as thrid and 1.7-1.8 times as long as fourth, elytra with short greyish stripe at the base of third interval longer than following black stripe if present.

30(31) Antennae very slender, second segment of funicle about 1.6 times as long as first, fourth to sixth segments twice as long as broad, fore tibiae dilated internally in the middle; 5.5-5.7 mm. ..................... Acicnemis sauteri Hubenthal

31(30) Antennae less slender, second segment of funicle about 1.2 times as long as first, fourth to sixth segments much less than twice as long as broad; 3.7-5.5 mm.

............... Acicnemis Euteomaculata sp. nov.

32(1) Hind tibiae evenly curved from base to apex, with almost of the same width throughout, except for weak dilation close to inner apical comer.

33(34) Hind tibiae scarcely exceeding posteriorly beyond apex of elytra; antennae robust, third to seventh segments of funicle moniliform, club without neck; conjoint postmedian band flat $\mathrm{V}$-shaped, greyish, sixth interval at base and broad apical area of elytra greyish, dorsal area between fifth striae before postmedian band almost blackish mixing some dark greyish patches; 3.1-4.0 mm.

Acicnemis postica Hubenthal

34(33) Hind tibiae slender, much exceeding posteriorly beyond apex of elytra, point of tooth a little beyond it; antennae slender, funicle much longer than broad, club with neck; scaling predominantly greyish brown on elytra, with dark brown patch in front of postmedian greyish indefinite patch, often with one to four dark brown patches on each margin and a pair of patches behind postmedian band; 2.2-3.2 mm.

*.....*. Acicnemis exilis sp. nov.

\section{Acicnemis albofasciata (Ter-Minasyan)}

(Figs. 10, 11, 83-91)

Trachodes albofasciatus Ter-Minasyan, 1953, Trud. zool. Inst. Akad. Nauk SSSR, 12: 317 (Maritime Province).

Acicnemis albofasciata: Zherichin \& Egorov, 1990, Curc. Russ. Far East: 50 (=nigra Nakane).

Acicnemis nigra Nakane, 1963, Fragm. Coleopt., (9): 37 (Type-locality: Sounkyo; Aomori,

Nagano). - Nakane, 1963, Icon. Ins. Jap. col. nat. ed., II: 369, pl. 185, fig. 8 (Hokkaido,

Honshu). - Morimoto, 1984, Coleopt. Jpn in col., IV: 325, pl. 64, fig. 6 (Hokkaido,

Honshu, Shikoku, Kyushu).

Easily distinguished by the M-shaped white postmedian band on blackish general scaling, but the band variable, often flat $\mathrm{V}$-shaped by the lack of posterior extensions on foruth and fifth intervals, or often extending laterally as far as seventh interval; ground scaling of elytra entirely blackish except for white patches in the specimens from Hokkaido and some other localities, but dark grey or dark brown scales more or less intermixed in some specimens from Honshu, 
Shikoku and Kyushu especially on declivity; length excluding neck (width) of antenna1 segments of funicle and club segments as $33(16): 33(11): 13(13): 13(13): 12(13): 12(14)$ : 15(15):57(32); male aedeagus with penis almost parallel-sided on basal half, then gently narrowing apically in weak curve and shortly pointed at apex, internal sac with spiny asperate broad area at apical third, with a pair of small sclerites at base of basal asperate area.

Length: 4.5-5.6 mm. (excl. rostrum).

Distribution: Japan (Hokkaido, Honshu, Shikoku, Kyushu); Saghalien, Maritime Territory.

Specimens examined: 121 exs. from Saghalien (Kawakami), Hokkaido (Akan, Mt. Daisetsu, Ashoro, Kamiotonbetsu, Mt. Nipesotsu, Horoka, Mitsumata-rindo, Nakayama-toge), Aomori (Shimokita, Towada), Akita (Mt. Chokai), Iwate (Mt. Hayachine), Niigata (Sasagamine), Fukushima (Yunohana spa), Gunma (Mt. Shirane, Mt. Hotaka), Tochigi (Oku-Nikko), Nagano (Shirahone, Bandoko), Shizuoka (Misakubo), Nara (Yoshino), Wakayama (Yoyasan), Hyogo (Akazaki), Tottrori (Mt. Daisen), Kochi (Mt. Tebako, Jinzenji), Ehime (Omogo), Fukuoka (Mt. Hiko), Oita (Mt. Sobo), and Kumamoto (Mt. Shiratori).

\section{Acicnemis nohirai sp. nov.}

(Figs. 12, 92-97)

Close to A. albofasciata having greyish postmedian band on blackish general scaling, but the scaling is almost entirely sooty black, postmedian band is narrower and interrupted by suture.

Derm black, except for reddish brown unci and claws; scaling almost entirely sooty black, with a pair of greyish to brownish grey narrow postmedian bands, greyish only along posterior margin of eyes, prosternum, median area of mesostemum, and narrow patches on legs, lateral stripes on pronotum absent, with velvety black patches as follows: lateral stripes along side margins of pronotum on basal half, a pair of basal patches in front of second and third intervals on pronotum, short stripe on the base of first interval, flat $\mathrm{V}$-shaped patch along anterior margin of postmedian band between fifth striae, transverse large patch on declivity, small patches at the base of second and fourth intervals, short stripes on fifth interval a little behind the base and on declivity, and on eighth interval at apical third, short oblique stripe behind shoulder between ninth and seventh intervals, pronotum with two pairs of black tufts, suberect greyish scales scattered on alternate intervals and legs.

Head between eyes a little narrower than the base of rostrum; rostrum weakly narrowing anteriorly to apical third, with slight expansion at antennae, and gradually widening again to apex, with weak median carina; antennae inserted at basal 2/5 (male) or 1/3 (female) of rostrum, with length excluding basal neck(width) of segments in funicle and club as 20(12):16(8):8(9) $: 8(9): 7(10): 8(11): 9(15): 46(21)$, club without neck. Pronotum as long as broad, broadest in the middle, slightly narrowing basally, densely punctate, not granulate. Scutellum tongueshaped, greyish. Elytra about 1.6 times as long as broad, parallel-sided until the level of postmedian band, intervals flat, almost of the same width throughout. Fore and middle tibiae triangularly expanded intervally in the middle, hind tibiae archedly expanded intervally at apical third. Male aedeagus with sclerite at the base of internal sac. Spermatheca slender, spermathecal gland and duct widely distant at base.

Length: 4.5-5.5 mm (excl. rostrum).

Distribution: Japan (Hokkaido, Honshu, Shikoku, Kyushu): 
Holotype: male (Type No. 2956, Kyushu Univ.), Hirayu, Gifu Pref., 19.iv.1963, T. Nohira leg.

Paratypes: Horoka, Kamishihoro-gun, Hokkaido, 1 female, 17.vii. 1976, H. Irie leg. Kawauchi, Shimokita-gun, Aomori Pref., 1 female, 28.vii.1984, S. Yamauchi leg. Kurokawa, Niigata Pref., 1 male, 30.vii.1962, K. Baba leg. Chuzenji-Yumoto, Tochigi Pref., 22.vii.1928, T. Esaki leg. Fuji-rindo, Yamanashi Pref., 1 male, 10-12.viii.1976, H. Irie leg. Mt. Kaikoma, Yamanashi Pref., 1 female, 13.viii.1962, K. Oshima leg. Tobira spa, Nagano Pref., 1 male, 7.viii.1973, T. Mikage leg. Same data as holotype, 3 males and 2 females. Omogokei, Ehime Pref., 1 female, 15.vi.1981, S. Naomi leg. Kurasame, Kuju, Oita Pref., 1 male and 1 female, 15.vi.1975, H. Irie leg.

Name of this new species is dedicated to our friend, Mr. Teruo Nohira, who is a keen entomologist in Gifu Prefecture.

\section{Acicnemis dividicincta sp. nov.}

(Figs., 13, 98-103)

Derm black, except for reddish brown antennae and tarsi; scaling dense, variegated with greyish brown, dark brown and black scales; rostrum with greyish brown, head greyish brown with a pair of dark brown patches, with greyish narrow fringe along dorsal and hind margins of eyes, with a few erect greyish scales along dorsal margin of eye and scattered greyish brown ones on basal scaled area of rostrum; pronotum with greyish brown except for median broad dark brown to blackish area, median area often greyish brown before the middle, or often subdivided by cruciform or T-shape pale brown patch, suberect scales sparse, not forming tufts; elytra with greyish postmedian patch divided by suture, each comma-shaped and inclined intero-posteriorly, with fringed velvety black patches anteriorly, with short velvety black stripe at the base of first and second intervals, often with a pair of indefinite velvety black patches on declivity, with short velvety black patches on seventh and ninth intervals in front of middle, behind the middle and near apex, suberect scales sparse on alternate intervals greyish around postmedian patches, blackish on the other part; legs with ground pattern as in fig.103, with sparse suberect greyish brown scales; underside greyish with brownish indefinite patches on second ventrite.

Rostrum as in A. nohirai; antennae with length(width) of segments in funicle and club as $19(12): 20(19): 11(9): 11(9): 9(9): 10(10): 12(11): 44(24)$, club without neck. Pronotum 1.1-1 .2 times as broad as long, broadest in the middle, weakly rounded laterally, disk densely punctate, not granulate, weakly convex dorsally, flattened transversely along hind margin. Scutellum ovate, with greyish brown scales. Elytra 1.6-1.7 times as long as broad, almost parallel-sided on basal half; striae well impressed, with distant punctures; intervals flat, much broader than striae. Femora with sharp teeth. Fore and middle tibiae bisinuate and weakly dilated internally in the middle, hind tibiae strongly dilated internally at apical third. Male aedeagus parallel-sided, with subtriangular apex, internal sac without sclerite. Spermatheca curved, well projected basally, spermathecal gland and duct close to each other at base.

Length: 4.3-5.4 mm (excl. rostrum).

Distribution: Japan (Honshu, Shikoku, Kyushu).

Holotype: male (Type No. 2957, Kyushu Univ.), Mt. Gagyuzan, Takahashi City, Okayama 
Pref., 19-20.v.1975, H. Irie leg.

Paratypes: Mt. Ohtoh, Wakayama Pref., 1 female, 7.viii.1980, I. Matoba leg. Same data as holotype, 1 male and 2 females. Mt. Tebako, Kochi Pref., 1 male and 1 female, 7-10.viii.1957, K. Morimoto leg. Mt. Hikosan, Fukuoka Pref., 1 female, 5.ix.1988, K. Morimoto leg. Mt. Kumado, Fukuoka Pref., 1 male, 31 .v.1959, Y. Miyake leg. Unzen, Nagasaki Pref., 1 male and 2 females, 18.vii.1946, M. Moritsu \& Y. Kurosawa leg.

\section{Acicnemis dividicincta okinawana subsp. nov.}

(Figs. 14, 15, 104-107)

Pronotum usually with two greyish stripes, one at inner margin of greyish brown lateral area in front of fifth interval and the other below the side margin in entire length, elytra with a pair of velvety black patch on declivity of third to fifth intervals, antennae slenderer, fourth and sixth segments about 1.2 times as long as broad, with length excepting neck(width) of segments of funicle and club as 21(13):25(10):12(9):12(10):10(10):13(11):15(13):47(24).

Length:4.9-6.4 mm (excl. rostrum).

Distribution: Japan (Amami-Oshima and Okinawa isls.).

Holotype: male (Type No. 2958, Kyushu Univ.), Hiji, Okinawa, 8.vii.1974, T. Mikage leg.

Paratypes: Same locality as holotype, 3 males and 2 females, 3-9.vii.1974, T. Mikage leg. Torigamine, Amami-Oshima, 1 female, 30.vi. 1976, N. Morishima leg.

\section{Acicnemis yakushimana sp. nov.}

(Figs. 16, 108-111)

Very close to A. dividicincta, but antennal funicle is slenderer, third segment is about 1.5 times as long as broad and 1.5 times as long as fourth, and pronotum is almost concolorous except for stripe on each side in front of fifth interval.

Derm blackish, except for dark reddish brown antennae and tarsi; scaling predominantly dark brown to brownish black, much darker than A. dividicincta; rostrum with dark brown to brownish black scales on basal area, with blackish suberect scales, head dark brown with greyish fringe along dorsal and hind margins of eyes, with a pair of blackish patches, pronotum almost dark brown to blackish brown, with a stripe on each side in front of fifth interval, which greyish at base and becoming brownish and indefinite anteriorly in front of the middle, with a pair of blackish patches behind the middle; elytra with a pair of greyish to brownish grey postmedian patches on second to fourth intervals, often diminished or vestigial on fourth interval, velvety black patches often indefinite in darker specimens, but present as in A. dividicincta okinawana, suberect scales predominantly blackish brown or partly greyish on fifth and seventh intervals; legs brownish black with small greyish patches and scattered greyish suberect scales; underside almost greyish, with brownish patches on first and second ventrites at sides and third and fourth ventrites in the middle.

Rostrum almost parallel-sided from the base to antennae, there slightly narrowed and then parallel-sided and then slightly widening again towards apex, with a median and two pairs of lateral carinae behind antennae, punctures before antennae gradually diminish apically, often 
with hairy scales until apical third in male, punctures much finer in female; antennae inserted a little behind the middle in both sexes, length excluding basal neck (width) of segments in funicle and club as $29(16): 31(11): 17(11): 15(11): 16(11): 15(13): 17(15): 55(27)$. Pronotum about 1.05 times as broad as long, broadest in the middle, slightly narrowing posteriorly in a weak curve or straight, densely punctate, interstices between punctures much narrower than their diameter, slightly depressed transversely along hind margin. Scutellum tongue-shaped, with greyish brown scales. Elytra 1.6-1.7 times as long at suture as broad, parallel-sided on basal half, intervals flat, much broader than striae. Fore and middle tibiae expanded internally in the middle, hind tibiae archedly expanded internally at apical third. Male aedeagus as in A. dividicincta, but internal sac with a sclerite at gonopore.

Length: 6.0-6.4 mm (excl. rostrum).

Distribution: Japan (Yakushima I.).

Holotype: male, (Type No. 2959, Kyushu Univ.), Miyanoura, Yakushima I., 26.vii.1974, T. Mikage leg.

Paratypes: Same locality as holotype, 2 males and 8 females, 26-29.vii.1974, T. Mikage leg. Shiratani, Yakushima I., 1 female, 26.vii.1974, T. Mikage leg. Mt. Tachudake, Yakushima I., 2 males and 2 females, 20.vii. 197 1, H. Irie leg.

Note: This new species is very close to A. dividicincta and needs to be revised these species by the accumulation of material from the adjacent islands.

\section{Acicnemis palliata Pascoe}

(Figs. 18, 19, 112-114)

Acicnemis palliata Pascoe, 1872, J. Linn. Soc. Lond., XI: 462 (Japan). - Roelofs, 1875, Ann. Soc. Ent. Belg., XVIII: 153 (sur les troncs ligneux de la Wisterea).- Hubenthal, 1917, Arch. f. Naturg., 83 A(8): 109, 118;(9): 71 (Japan, China?: Ho Chan). - Morimoto, 1959, Enum. Ins. Mt.Hikosan, II: 82 (oviposited to Wistaria floribunda). - Iga, 1956, Col. Illust. Ins. Jpn, Coelopt. (rev. ed.): 219, pl. 68, fig. 1559 (Honshu, Shikoku, Kyushu). - Nakane, 1963, Icon. Ins. Jpn col. nat ed., II: 369, pl. 185, fig. 7. - Morimoto, 1984, Coleopt. Jpn in col., IV: 325 , pl. 64 , fig. 5 .

Derm blackish, except for dark reddish brown antennae and tarsi; scaling dense, brownish grey, with blackish median area of pronotum behind the middle and broad heptangular dorsal area before tansverse postmedian band, head greyish brown with a pair of brownish patches, with a row of several erect scales on each side of frons, rostrum with dark brownish scales on basal area, pronotum with median blackish patches becoming brownish anteriorly before the middle, often divided medianly by a faint brownish stripe, with a transverse row of four tufts in the middle, of which lateral ones often diminished and median pair often blackish, and also similar tuft at anterior margin; elytra with median heptangular black area surrounded by brownish grey area, postmedian band only slightly more greyish than behind area, black velvety black short stripes at the base and in the middle of first interval, the latter continuous to anterior border of postmedian patch and anchor-shaped, another short velvety short stripes often present on fifth interval behind the base and on seventh interval in front of the middle, suberect scales on alternate intervals same colour as to the ground scales, underside and legs almost brownish grey, except for a pair of blackish patches on second ventrite. 
Rostrum with a median and two pairs of lateral carinae behind antennae, which inserted in $2 / 5$ of rostrum from base, length(width) of segments in funicle and club as $27(22): 34(12): 18(12)$ $: 15(12): 14(12): 14(14): 19(18): 54(30)$. Pronotum 1.05-1.08 times as broad as long, almost parallel-sided on basal half, with dense punctures. Scutellum tongue-shaped, with brownish grey scales at margins and bare on dorsum. Elytra 1.551 .67 times as long as broad, parallel-sided on basal half, intervals flat, much broader than striae. Hind legs greater and robuster than anteriors, hind tibiae especially robust, with strong expansion internally at apical third. Male aedeagus with penis parallel-sided from base to middle, then evenly narrowed to apex in a continuous curve, internal sac with a pair of comma-shaped large sclerites at gonopore.

Length: $5.0-6.9 \mathrm{~mm}$ (excl. rostrum).

Distribution: Japan (Honshu, Shikoku, Kyushu, Tsushima), China (?).

Specimens examined: 44 specimens from Niigata (Senami), Ishikawa (Kanazawa), Shizuoka (Misakubo), Fukui (Kinome-toge), Gifu (Mt. Ibuki), Nara (Kasuga), Osaka (Mt. Iwawaki), Hyogo (Mt. Maya), Okayama (Kurashiki), Tottori (Mt. Daisen), Tokushima (Minaminoma), Kochi (Kodakasa, Mt. Kuishi), Fukuoka (Mt. Hikosan, Fukuoka, Kashii, Odo, Mt. Homan, Mt. Korasan), Kumamoto (Mt. Iida), Kagoshima (Kagoshima), and Tsushima (Izuhara).

Biology: Weevils are common on dead or woody stem of ornamental Wistaria floribunda (Fuji in Japanese) from late April to August and larvae mine the large stem.

\section{Acicnemis shigematsui sp. nov.}

(Figs. 20, 21, 115)

Very close to A. palliata in coloration and structures, but different in the following points:

Elytra with postmedian band and apical brownish grey area divided by narrow blackish band, black velvety patched absent or indefinite, venter brownish except for greyish median area on first and second ventrites. Length (width) of segments in funicle and club as 28(16):31(11): $16(11): 14(11): 13(12): 14(13): 18(16): 50(28)$.

Length: 5.9-6.3 mm (excl. rostrum).

Distribution: Japan (Ryukyus: Ishigaki and Iriomote isls.).

Holotype: male (Type No. 2960, Kyushu Univ.), Mt. Omotodake, Ishigaki I., 1.viii.1989, K. Shigematsu leg.

Paratypes: Shirahama, Iriomote I., 1 male, 31.viii-5.ix.1969, H. Makihara leg. Mt. Ushiku, Iriomote I., 1 female, 4.xi.1963, G. A. Samuelson leg. Upper Nakara riv., Iriomote, 1 female, 12.iii.1964, Y. Miyatake leg.

Name of this new species is dedicated to our friend, Mr. Kazumi Shigematsu, who is a good collector of weevils.

\section{Acicnemis suturalis Roelofs}

(Figs. 22, 116-121)

Acicnemis suturalis Roelofs, 1875, Ann. Soc. ent. Belg., XVIII: 154 (Kobe). - Hubenthal, 1917, Arch. f. Naturg., 83 A (8): 105, 118; (9): 72 (Kobe \& Formosa). - Nakane, 1963, Icon. Ins. Jpn col. nat. ed., II: 369, pl. 185, fig. 9. - Morimoto, 1984, Coleopt. Jpn in col., IV: 326, pl. 64, fig. 11 . 
Somewhat isolate species among Asian species in having the following characters:

Derm blackish except for dark reddish brown antennae and tarsi; scaling dense, head greyish, rostrum greyish brown at base, prothorax brownish grey with three dark brown stripes on each side, of which outermost one on lateral side, elytra predominantly dark brownish to brownish black, with whitish postmedian patches absent or small and indefinite on second and third intervals if present, with distinct greyish transverse band in entire width, which produced posteriorly on median intervals and fringed transversely along anterior margin with blackish band, velvety black stripe distinct on basal third of first interval, similar but narrower velvety stripes often present on the base of fifth interval and also on third interval in the middle, underside greyish, often with dark spot on each side of second and fifth ventrites.

Antennae robust, club without neck, length(width) of segments in funicle and club as 18(11) $: 14(7): 7(8): 7(8): 7(8.5): 7(9): 8(12): 49(24)$. Tibiae weakly dilated internally a little behind the middle, apico-interior corners rounded in male, normally angulate or pointed in female. Male aedeagus with penis almost parallel-sided in the middle, dilated posteriorly and acuminate apically, internal sac with two rows of dense robust spines by gonopore.

Length: 3.4-4.0 mm (excl. rostrum).

Distribution: Japan (Honshu, Shikoku, Kyushu), Taiwan (after Hubenthal, 1917).

Specimens examined: 52 specimens from Niigata (Senami), Chiba (Mt. Kiyosumi), Nagano (Karuizawa), Fukui (Koike), Kyoto (Katsura-gawa), Nara (Kasuga), Kobe (Mt. Maya), Wakayama (Mt. Ohtoh), Kochi (Mt. Kuishi), Ehime (Mt. Ishizuchi), and Fukuoka (Mt. Fukuchi, Mt. Hikosan, Mt. Joyama, Mt. Wakasugi, Mt. Homan, Mt. Sefuri, Magaribuchi).

Biology: Many weevils were found on dead vine of Wistariabrachybotrys (Yamafuji in Japanese) at Mt. Wakasugi.

\section{Acicnemis dorsonigrita Voss}

(Figs. 23, 122-125)

Acicnemis dorsonigrita Voss, 1941, Mitt. Münch. Ent. Ges., 31: 889 (Unzen Shimabara, Tienmuschan). - Nakane, 1963, Icon. Ins. Jpn col. nat. ed., II: 369, pl. 185, fig. 6. Morimoto, 1984, Coleopt. Jpn in col., IV: 326, pl. 64, fig. 10.

Scaly pattern is almost the same as A. palliata, but suture has a velvety black spot behind postmedian band.

Antennae inserted in the middle (male) or at posterior third of rostrum, robust, with lendth(width) of segments in funicle and club as 18(11):29(7):9(7):8(7):9(8.5):19(19): $14(11): 36(20)$, club without neck. Male aedeagus with penis parallel-sided, rapidly narrowed and bruntly pointed at apex, internal sac with spiny asperity on one side of apical area and dense spiny asperity in median and basal area.

Length: 2.9-4.0 mm (excl. rostrum).

Distribution: Japan (Hokkaido, Honshu, Izu Isls., Shikoku, Kyushu), China (Tienmushan).

Specimens examined: 73 specimens from Hokkaido (Ohnuma, Nukabira, Senpoku-toge), Niigata (Senami, Kurokawa), Sado (Ookura), Fukushima (Hinoemata), Gunma (Mt. Hotaka, Shima), Nagano (Ina, Honjo-mura, Tobira spa), Fukui (Obama, Kinome-toge), Osaka (MinooTakayama, Myoken), Wakayama (Koya), Okayama (Kamo), Tottori (Mt. Daisen), Tokushima (Mt. Tsurugi), Kochi (Engyoji, Mt. Tebako), Kumamoto (Naidaijin, Mt. Shiratori), and Izu Isis. 
(Niijima, Shikinejima).

\section{Acicnemis kiotoensis Nakane}

(Figs. 24, 128-1 34)

Acicnemis kiotoensis Nakane, 1963, Fragm. Col.,(9): 36 (Type-locality: Kurama, Kyoto; Yaku I.). - Nakane, 1963, Icon. Ins. Jpn col. nat. ed., II: 369, pl. 185, fig. 5 (Honshu). Morimoto, 1984, Coleopt. Jpn in col., IV: 325, pl. 64, fig. 8.

Derm blackish except for reddish brown antennae and tarsi; scaling predominantly ochreous to ochreous brown mixing black patches, postmedian patch of elytra ochreous grey between fifth intervals, often diminished on fourth and fifth intervals, conjoint subrhomboidal on second and third intervals, with velvety black stripes on third interval before postmedian patch and narrow band behind the patch on second and third intervals conspicuous, black small spots often present as follows: two spots behind the base and a spot on subapical callus of fifth interval, a conjoint spot behind shoulder and a conjoint spot in the middle of seventh and eighth intervals.

Antennae slender, with length(width) of segments in funicle and club as 22(14):29(10): 15( 10): 14(10):12(9):12(10):15(11):49(21), club with neck. Legs robust, with tooth sharp, fore tibiae dilated internally behind the middle. Penis parallel-sided, broadly rounded at apex with brunt point, internal sac without sclerite.

Lenght: 4.9-7.0 $\mathrm{mm}$ (excl. rostrum).

Distribution: Japan (Honshu, Kyushu, Tsushima, Yakushima I., Ryukyus: Amami-Oshima, Okinawa, Iriomote isls.), Taiwan.

Specimens examined: 52 specimens from Nara (Mt. Kasuga), Wakayama (Mt. Ohtou), Fukuoka (Mt. Hikosan), Kumamoto (Mt. Ichifusa), Miyazaki (Mt. Aoidake), Kagoshima (Mt. Kirishima), Tsushima (Mt. Tatera), Yakushima I., Amami-Oshima I., Okinawa I., Iriomote I., and Taiwan (Lushan, Shyk Shan near Liu Kui, Mt. Hsin-Kao-Shin Shan).

\section{Acicnemis sauteri Hubenthal}

(Figs. 25, 26, 126, 127)

Acicnemis sauteri Hubenthal, 1917, Arch. f. Naturg., 83 A(8): 104, 107, (9): 106 (Type-locality: Hoozan; Kosempo, Fuhosho, Taihorinsho).

Very close to smaller individuals of A. kiotoensis, but postmedian patches on elytra narrower and greyish, antennae slenderer, second segment of funicle more than three times as long as broad and 1.4-1 .5 times as long as third, fourth to sixth segments twice as long as broad, and fore tibiae dilated internally in the middle.

Antennae slender, with length(width) of segments in funicle and club as $23(15): 36(11)$ : 24( 10):20(10):20(10):18(11):12(20):67(26), club with neck. Legs slender, fore tibiae dilated internally in the middle.

Length: 5.5-5.7 $\mathrm{mm}$ (excl. rostrum).

Distribution: Japan (Nakanoshima I.)-new record, Taiwan.

Specimens examined: Nakanoshima, Tokaras, 1 female, 25-30.iv.1975, H. Irie leg. Lushan, Nantou Hsien, Taiwan, 1 female, 7.vi.1976, H. Makihara leg. 


\section{Acicnemis maculaalba Roelofs}

(Figs. 27, 135-140)

Acicnemis macula-alba Roelofs, 1875, Ann. Soc. ent. Belg., XVIII: 153 (Japon).

Acicnemis maculaalba: Hubenthal, 1917, Arch. f. Naturg., 83 A(8): 104, 120; (9): 103. -

Nakane, 1963, Icon. Ins. Jpn in col. nat. ed., II: 69, pl.185, fig.4. - Morimoto, 1984,

Coleopt. Jpn in col., IV: 325 , pl.64, fig.8.

Easily distinguished from the relatives by almost transverse posterior margin of whitish postmedian patches on elytra. Antennae with length(width) of segments in funicle and club as 20(13): 26(10):18(8):14(8):15(8):13(9):16(11):51(22), club with distinct neck. Femora with a pair of obtuse carinae on stalk, fore tibiae dilated internally in the middle. Male aedeagus with penis parallel-sided and blunt triangular at apex, internal sac with a pair of sclerites at gonopore, asperate in the basal and median areas.

Length: $3.5-4.8 \mathrm{~mm}$ (excl. rostrum).

Distribution: Japan (Honshu, Shikoku, Kyushu, Yakushima I., Kuchinoshima I., Nakanoshima I., Akusekijima I., Amami-Oshima I., Okinawa I., Ishigaki I., Iriomote I.), Taiwan.

Specimens examined: 45 specimens from Mie (Mie Univ. Forest), Wakayama (Mt. Ohtou), Kochi (Okinoshima I.), Fukuoka (Mt. Kumado), Kagoshima (Sata), Ryukyus (above mentioned islands), and Taiwan (Chulu, Taithun Hsien; Hungyeh Wenchuan, Hualien Hsien).

Note: This species seemed to be misidentified by Hubenthal (1917), because whose redescription fits well to an undescribed species from Taiwan in the collection of Kyushu University, which is very close to this species in shape and scaly pattern, but is different in the structure of the antennae. Senior author examined the type specimen at the Natural History Museum in London.

\section{Acicnemis luteomaculata sp. nov.}

(Figs. 28, 141-146)

Derm black except for reddish brown antennae, unci of tibiae and tarsi; scaling predominantly ochreous to greyish brown mixing greyish and blackish patches, head greyish with a pair of brown patches, forehead and base of rostrum brownish to greyish brown, with suberect dark brown scales, pronotum greyish brown, often with a greyish narrow stripe on each side in front of fourth interval to apical margin parallel to side margin, with two pairs of loosely assembled suberect brown scales, elytra with a pair of yellowish grey postmedian patches on second and third intervals, oblique and often continuous to greyish short indefinite band on fourth to sixth intervals on a level of hind margin of the patch on second interval, with a short stripe of the same colour at the base of third interval, black patches often present as follows: small spot at the base of second interval, small spot a little behind the base, short stripe in front of and small spot behind the postmedian patch on third interval, often with two to three spots each on fifth and seventh intervals, often spots on latter intervals transversely confluent and forming indefinite bands, underside almost greyish brown.

Rostrum gradually narrowing anteriorly from the base to apical fifth, then weakly widening apically, with punctures and carinae concealed by scales and median fine carina discernible in the middle; antennae inserted just behind the middle (male) or in the basal third (female), with 
length(width) of segments in funicle and club as $20(13): 22(8): 15(7): 13(7): 12(7): 12(7)$ : 12(8): 14( 10):50(24), club with distinct neck. Pronotum almost as long as broad, broadest in front of the middle, almost parallel-sided or slightly narrowing thence postreriorly, disk with dense punctures, weakly and evenly convex, not flattened along lateral margins. Scutellum oblong, with greyish brown scales. Elytra 1.4- 1.6 times as long as broad, parallel-sided on basal half, second stria curved outward at base, intervals flat, much broader than striae. Legs slender, femora with sharp tooth, stalk of hind femora as long as the club, tibiae dilated internally behind the middle. Male aedeagus with penis slender, parallel-sided, subtriangular at apex, internal sac with spatulate sclerite. Spermatheca with long base.

Length: $3.7-5.5 \mathrm{~mm}$.

Distribution: Japan (Honshu, Shikoku, Kyushu).

Holotype: male (Type No. 2961, Kyushu Univ.), Mt. Hikosan, Fukuoka Pref., 13-14.vi.1957, K. Morimoto leg.

Paratypes: Kasugayama, Nara, 1 male and 3 females, 5, 30 \& 31 .v.1959, K. Ueda leg.; 1 female, 25.vii.1959, T. Hozumi leg. Mt. Ohdaigahara, Nara Pref., 1 female, 2.vii.1978, H. Hiramatsu leg. Mt. Gomadan, Wakayama Pref., 1 male, 28.vii. 1979, I. Matoba leg. Mt. Gagyusan, Takahashi City, Okayama Pref., 1 male and 2 females, 19-20.v.1975, H. Irie leg. Mt. Tebako, Kochi Pref., 2 males and 1 female, 7-10.viii.1957, K. Morimoto leg. Erimon, Hongawa, Kochi Pref., 1 male, 13.ix.1952, H. Kashiwabara leg. Mt. Hikosan, Fukuoka Pref., 1 female, 10.vii.1938, Hori, Kawahara \& Yasumatasu leg.; 2 males and 1 female, 8.vi.1957, K. Morimoto leg.; 1 male and 1 female, 9.vi.1957, K. Yasumatsu leg.; 2 males and 1 female, 13-14.vi.1957, K. Morimoto leg.; 1 male and 3 females, 13.vii.1957, Y. Miyatake leg.; 1 male and 1 female, 4.vi. 1958, K. Morimoto leg. Mt. Homan, Fukuoka Pref., 1 female, 15.v. 1975, H. Irie leg. Mt. Wakasugi, Fukuoka Pref., 1 male and 1 female, 28.vii.1940, T. Shirozu leg.; 1 female, 18.xii. 1955, K. Ooshima leg.

Biology: Weevils were captured on bed log of Shiitake mushroom.

\section{Acicnemis azumai sp. nov.}

(Fig. 29, 147-151)

Close to A. laeta from Taiwan, but postmedian band greyish and open M-shaped with black fringe along posterior margin.

Derm dark reddish brown, with reddish brown antennae, rostrum and tarsi; scaling dense, predominantly greyish brown with black short stripes and greyish patches, head and basal area of rostrum greyish brown, pronotum greyish brown with greyish stripe in entire length in front of sixth interval, which curved parallel to side margin, with a pair of dark basal patches, with a transverse row of four tufts of erect scales in the middle, of which the lateral one greyish brown and small or indefinite, median one blackish, and a pair of similar scale behind anterior margin dark brown; elytra greyish brown with black patches as follows: stripe at the basal fourth of first interval, small spot behind the base and short stripe in the middle of third and fifth intervals, two or three spots each on seventh and ninth intervals, often these spots indefinite or absent, or continued transversely forming blackish bands, V-shaped black fringe along hind margin of postmedian band always present, median third of first interval between black patches often ochreous or yellowish brown and conspicuous, postmedian greyish band often diminished on 
fourth interval, alternate intervals with a row of scattered erect scales; undersurface brownish grey, with dark brownish patch on each side of second ventrite.

Rostrum gradually narrowing anteriorly from the base to apical fourth, then weakly widening apically; antennae inserted in the basal $2 / 5$ (male) or basal $1 / 3$ (female) of rostrum, with length excluding basal neck (width) of segments in funicle and club as 23(11):28(9):12(9):11(9): $11(9): 11(9): 12(11): 47(29)$, scaled from scape to sixth segment of funicle, club without neck. Pronotum 1.1-1.3 times as broad as long, broadest in front of the middle, thence scarcely narrowing posteriorly, disk with dense punctures, one or two pairs of punctures larger and deeper in front of scutellum, evenly and weakly convex dorsally, not depressed along side margins. Scutellum ovate, with greyish brown scales. Elytra almost parallel-sided on basal 3/5, intervals flat, a little broader than striae. Hind femora shortly exceeding posteriorly beyond apex of elytra, stalk longer than club, hind tibiae strongly dilated internally at apical third. Male aedeagus with penis broadest in front of the middle, straightly and slightly narrowing basally and narrowing anteriorly in a curve and triangular at apex, internal sac asperate at basal area, without sclerite.

Length: $3.6-4.2 \mathrm{~mm}$ (excl. rostrum).

Distribution: Japan (Nakanoshima, Amami-Oshima, Okinoerabu, Aguni, Tonaki, Okinawa, Miyako, Ishigaki, Iriomote and Hateruma Isls.).

Holotype: male (Type No. 2962, Kyushu Univ.), Kudeken, Chinen-son, Okinawa I., 22.iv.1975, H. Irie leg.

Paratypes: Nakanoshima I., Tokaras, 1 male and 1 female, 1-2.v.1975, H. Irie leg.; 2 males and 1 female, 4.viii.1989, T. Ueno leg. Nishinakama, Amami-Oshima I., 1 female, 3-5.viii.1969, H. Makihara leg. Okinoerabu I., 1 male, 9.v.1957, M. Umebayashi leg. Same data as holotype, 3 males and 4 females. Oku, Okinawa I., 89, 15-17.v.1978, H. Makihara leg. Chinen, Okinawa I., 7 males and 4 females, 22.v.1978, H. Makihara leg.; 1 female, 31.v.1976, T. Ogasawara leg. Yona, Okinawa I., 2 males and 2 females, 9-13.viii.1969, H. Makihara leg.; 1 female, 16-20.v.1978, H. Makihara leg. Yonahadake, Okinawa I., 1 male and 1 female, 29.v.1978, H. Makihara leg. Sueyoshi, Naha, Okinawa I., 1 female, 9.vii.1987, T. Ueno leg.; 5 males, 5.vi.1988, T. Ueno leg. Mabuni, Okinawa I., 1 male and 2 females, 1 l.iv.1977, H. Irie leg. Tamagusuku, Okinawa I., 2 males and 1 female, 23.viii.1962, M. Kina leg. Nago, Okinawa I., 1 male, 18.vi.1934, T. Esaki leg. Naha, Okinawa I., 1 female, 13.viii.1952, K. Hamamatsu leg. Shuri, Okinawa I., 1 male, 14.vi.1958, 0. Nakachi leg.; 1 male, 5-9.v.1969, H. Makihara leg. Hyakuna, Tamagusuku, Okinawa I., 1 male and 1 female, 18.vi.1970. H. Makihara leg. Tonaki I., 1 male and 2 females, 27.ix.1989, T. Ueno leg. Aguni I., 3 males and 1 female, 24-25.viii.1989, T. Ueno leg. Akajima I., 1 female, 29-30.viii.1989, T. Ueno leg. Shimozato, Miyako I., 1 female, l.ix.1958, T. Hidaka leg. Mt. Omoto, Ishigaki I., 1 female, 30.viii.1962, M. Okabe leg.; 1 female, 23-26.v.1990, K. Morimoto leg.; 1 male and 1 female, 18-22.vi.1991, K. Morimoto leg. Mt. Banna, Ishigaki I., 1 female, 27-31 .x. 1963, Y. Hirashima leg. ; 1 female, 7-9.ix.1969, H. Makihara leg.; 1 female, 30.vii.1970, I. Matoba leg. Yoshihara, Ishaigaki I., 1 female, 15.x.1963, K. Morimoto leg. Takeda, Ishigaki I., 1 male, 20.iv.1981, K. Baba leg. Otomi, Iriomote I., 3 males and 4 females, 12 \& 25.iv.1969, H. Makihara leg. Shirahama, Iriomote I., 2 females, 4.x.1963, S. Miyamoto \& K. Morimoto leg.; 1 male and 2 females, 31.viii-5.ix.1969, H. Makihara leg. Komi, Iriomote I., 1, 12.vii.1963, Y. Miyatake leg. Iriomote I., 8 males and 6 females, 26-27.vii.1962, Y. Hama leg. Hateruma I., 2 males, 22-24.vi.1977, H. Irie lg. 
Name of this new species is dedicated to Prof. Seiji Azuma of University of the Ryukyus in honor of his great contribution to various fields of entomology in the Ryukyus.

\section{Acicnemis postica Hubenthal}

(Figas. 31, 157-162)

Acicnemis postica Hubenthal, 1917, Arch. f. Naturg., 83A (8): 109, 118; (9): 73 (Fuhosho, Kankau: Koshun).

This small and beautiful specis is easily recognized by the hind tibiae, which are evenly curved and almost of the same width throughout except for weak dilation close to inner apical corner.

Derm black except for reddish brown antennae and tarsi, often tibiae dark reddish; scaling dense, greyish brown mixing greyish and blackish scales; pronotum with two greyish stripes on each side, one along side margin in front of fourth to seventh intervals and the other below side margin, with a pair of black basal patches, with a transverse row of four scaly tufts, median pair blackish brown, outer pair brownish grey, small and often obsolete, with similar tufts at anterior margin in front of median pair, but smaller; elytra with postmedian band V-shaped between third intervals, greyish brown to white on second and third intervals and posterior fringe and suture greyish brown, median large area surrounded by postmedian band, third striae in the middle and fifth striae at base black, transverse black median band weakly arched, shortly produced anteriorly on third interval and interrupted by suture, seventh interval often with two black spots, apical area behind black band on declivity brownish grey to greyish brown; undersurface ash grey, with a brown spot on each side of second ventrite, often lateral and posterior areas of venter brownish.

Antennae inserted in $2 / 5$ (male) or $1 / 3$ (female) of rostrum from the base, robust, with length (width) of segments in funicle and club as $20(12): 14(7): 8(8): 7(8): 7(8): 8(10): 9(12)$ : 34(22), club without neck. Pronotum 1.1-1.3 times as broad as long, broadest in the middle, weakly rounded laterally, disk densely punctate, slightly depressed longitudinally along side margins. Scutellum ovate, convex, brownish. Elytra 1.5 times as long as broad, parallel-sided on basal half, intervals flat, much broader than striae. Male aedeagus with penis broadest at base, rounded at apex, internal sac with a pair of tufts of brown large spines in the middle, asperate in the middle and basal areas.

Length: 3.1-4.0 mm (excl. rostrum).

Distribution: Japan (Kyushu, Ryukyus from Yakushima I. to Yonaguni I.), Taiwan.

Specimens examined: 155 specimens from Miyazaki (Miike, Ebino City), Kagoshima (Mt. Kirishima), Yakushima, Nakanoshima, Kuchinoshima, Amami-Oshima, Okinawa, Kumejima, Ishigaki, Iriomote and Yonaguni Isls., and Taiwan (Kenting, Lushan, Chihpon, Palin, Liu Kui, Jiuyuehtan).

\section{Acicnemis shibatai Voss}

(Figs. 30, 152-156)

Acicnemis shibatai Voss, 1971, Mem. Fac. Educ., Kagawa Univ., II(202): 52 (Amami-Oshima: Ikari, Hatsuno). - Morimoto, 1984, Coleopt. Jpn in col., IV: 326, pl.64, fig.9. 
Characteristic by the cordiform postmedian patch on elytra. Scaling generally brownish to greyish brown, pronotum broadly blackish in the middle, elytra with a cordiform brownish grey to white cordiform patch, which fringed by blackish belt, with blackish lateral stripe arising from ninth interval and transferred to eighth interval shortly behind shoulder, another blackish stripe on basal quarter of second interval, then transferred to third interval and continuous to anterior fringe of postmedian patch, dorsal area between the latter usually dark brownish to blackish; underside greyish, with brownish patch on each side of second ventrite.

Antennae inserted in $2 / 5$ (male) or $1 / 3$ (female) of rostrum from the base, robust, with length (width) of segments in funicle and club as $19(10): 13(7): 8(7): 8(7): 8(7.5): 7(8): 10(11)$ : $36(21)$, club without neck. Pronotum about 1.1 times as broad as long, broadest in the middle, scarcely narrowed basally, disk densely punctate, evenly convex, not depressed along side margins. Scutellum tongue-shaped, convex, greyish brown to brownish. Elytra 1.6-1.7 times as long as broad, parallel-sided on basal $2 / 3$, intervals flat, much broader than striae. Hind tibiae triangularly expanded internally at apical third. Male aedeagus with penis slender, parallel-sided, with subtriangular apex, internal sac with a median dense asperity in the middle and a pair of similar asperities at base, ninth stemite divided medianly.

Length: 3.2-3.6 mm (excl. rostrum).

Distribution: Japan (Honshu, Shikoku, Kyushu, Tsushima, Shimo-Koshikijima, Yakushima, Nakanoshima, Kuroshima, Amami-Oshima, Tokunoshima, and Iriomote Isls.), Taiwan (Wulai).

Specimens examined: 89 specimens from Chiba (Mt. Kiyosumi), Kochi (Shimizu, Okinoshima I.,), Fukuoka (Mt. Joyama, Mt. Kosho, Ohmuta), Kumamoto (Tatsudayama), Tsushima (Azamo, Izuhara, Mt. Tatera), Shimo-Koshikijima (Teuchi), Nakanoshima I., Kuroshima I., Amami-Oshima (Hatsuno, Mt. Yuwandake, Chuo-rindo, Nishinakama, Ishihararindo), Tokunoshima I. (Mikyo), Iriomote I. (Shirahama), and Taiwan (Wulai).

\section{Acicnemis exilis sp. nov.}

(Figs. 32, 163-167)

Close to A. meriones Pascoe and its relatives in having slender body, very long hind femora, which exceeding posteriorly far beyond apex of elytra and the narrow stalk much longer than the club, the greyish postmedian patches on elytra small or indefinite with contiguous blackish patches in front, and erect scales usually narrower and long on alternate intervals, but present new species is characteristic in the shape of hind tibiae, which curved evenly and of the same width throughout except for weak internal dilation close to apex, tooth of hind femora reaching the apex of elytra, ground scaling almost concolorous on pronotum, elytra with small black spots on first and second intervals at base surrounding greyish brown scutellum, and erect scales on alternate intervals of elytra weakly clavate, about three times as long as broad and about 1.5 times as long as the median breadth of first interval.

Derm reddish brown; scaling dense, predominantly greyish brown, head often brownish on vertex and greyish between eyes, rostrum and forehead with several erect scales in a row on each side, pronotum often with an indefinite greyish small patch on each side of the base in front of fourth to sixth intervals, a few erect dark brownish to greyish brown scales grouped together in two pairs, one at anterior margin, the other in the middle, and also with several erect brownish grey scales scattered along side margins, elytra with a pair of greyish postmedian patches on 
second to fourth intervals, those on third interval always present but often diminished or absent on second and fourth intervals, with blackish patch in front of postmedian patch on second to fourth intervals variable in size, often with dark brownish patch behind it on declivity, usually with two dark brownish patches on each side on eighth to tenth intervals in front and behind the middle, sometimes with brownish grey short stripe at the base of third interval, undersurface and side margins of elytra snow white except for brownish median area of mesepimera and greyish brown anterior half of metepisterna.

Rostrum with a median and two pairs of lateral carinae from forehead to apical fourth and longitudinally punctate between them before antennae in male, those on basal half and diminished anteriorly in female; antennae inserted in basal third (male) or fourth (female), with length (width) of segments in funicle and club as 13(10):14(6):9(6):9(6):9(6):S(6) : 19(7):32(16), club fusiform, with neck. Pronotum as long as broad, broadest in the middle, gently rounded laterally and shortly parallel-sided at base, posterior margin strongly bisinuate, scarcely broader than anterior margin, disk densely punctate, evenly convex dorsally. Scutellum oblong-ovate. Elytra 1.7-1.9 times as long as broad, parallel-sided on basal two-thirds, punctures in striae large, broader than intervals or septa between them, but usually concealed by scales and visibly narrower than intervals. Hind femora with slender and arched stalk, its tooth reaching the apex of elytra in lateral aspect, fore and middle tibiae slightly dilated internally at apical third, hind tibiae evenly curved, same width throughout and weakly dilated internally close to apex. Male aedeagus with penis almost parallel-sided and subtriangular at apex, internal sac with a faint ring at basal area.

Length: 2.2-3.2 $\mathrm{mm}$ (excl. rostrum).

Distribution: Japan (Kuchinoshima, Nakanoshima, Amami-Oshima, Ishigaki and Iriomote Isls.).

Holotype: male (Type No. 2963, Kyushu Univ.), Naze, Amami-Oshima I., 27.v.1978, T. Tsutsumi leg.

Paratypes: Kuchinoshima I., 1 female. 26.vi-3.vii.1969, H. Makihara leg. Nakanoshima I., 1 female, 4.viii.1989, T. Ueno leg. Same data as holotype, 1 male and 6 females. Nishinakama, Amami-Oshima I., 1 male, 3-5.viii.1969, H. Makihara leg. Mt. Omotodake, Ishigaki I., 2 males and 5 females, 30.vii.1962, M. Okabe leg.; 1 male, 14.x.1963, S. Miyamoto leg.; 1 male, 31.vi.1971, I. Matoba leg. Yoshihara, Ishigaki I., 1 male, 16.x.1963, S. Ueno leg. Kaarayama, Ishigaki I., 1 male and 1 female, 14.iii.1964, Y. Miyatake leg. Toro-gawa, Ishigaki I., 2 females, 17.iii.1964, Y. Miyatake leg. Ishigaki I., 1 female, 24.iii.1980, A. Ishida leg.; 31, 21.iv.1984, K. Iha leg. Shirahama, Iriomote I., 1, 4.x.1963, K. Morimoto leg.; 2 males and 3 females 31.viii5.ix.1969, H. Makihara leg. Sonai, Iriomote I., 1 male, 25-29.viii.1969, H. Makihara leg. Ushikunomori, Iriomote I., 1, 7.viii.1962, M. Sato et Y. Arita leg. Urauchi, Iriomote I., 1 female, 22.iv.1981, K. Baba leg. Iriomote I., 1 male and 1 female, 27.vii.1962, Y. Hama leg.

\section{Acknowledgments}

We would like to express our thanks to the following entomologists for their kind help on materials: Mr. A. Abe, Prof. S. Azuma, late Dr. K. Baba, Dr. M. Chûjô, Mr. M. T. Chûjô, Mr. K. Emoto, Mr. H. Ichihashi, Mr. H. Irie, Prof. S. Kimoto, Prof. K. Kojima, Mr. H. Kojima, Dr. Y. 
Kurosawa, Mr. H. Makihara, Mr. I. Matoba, Mr. T. Mikage, Mr. Y. Miyake, Prof. S. Miyamoto, Mr. Y. Miyatake, Prof. Y. Murakami, Mr. K. Nakata, Mr. T. Nohira, Dr. K. Oshima, Dr. M. Sakai, Prof. H. Sasaji, Prof. M. Sato, Mr. K. Shigematsu, Prof. T. Shirôzu Prof. I. Togashi, Dr. S. Uéno, Mr. T. Ueno, and Mr. S. Yamauchi.

\section{A bibliography for the systematics of Asian Acicnemidinae}

Chevrolat, A. 1878 Nouvelles espèces du genre Acicnemis de Fairmaire. Petit. nouv. Ent., 2: 203.

Chevrolat, A. 1878 Du genre Acicnemis. Petit. nouv. Ent., 2: 206.

Chevrolat, A. 1882 Diagnoses de Coléoptères des iles Adaman [Andaman]. Naturaliste, 2: 9394, 133-134.

Fairmaire, M. L. 1849,50 Essai sur les Coléoptères de la Polynesie. Rev. Mag. Zool., (2)1: 277291, 352-365, 410-422, 445-460, 504-516, 550-559, pl.II; 1850. (2)2: 50-64, 115-122, 181-185.(ref.504-516),(sep.1-102, lpl., 1849).

Faust, J. 1892 Contributions à la faune indo-chinoise (10 $\mathrm{e}$ mem.). Curculionidae, Brenthidae. Anin. Soc. ent. Fr., LXII: 505-522.

Faust, J. 1894 Viaggio di Leonardo Fea in Birmania e regioni vicine. LX. Curculionidae. Ann. Mus. Stor. Nat. Genova, XXXIV: 153-370.

Faust, J. 1896 Neue Curculioniden aus Java. Stett. ent. Zeit., LVII: 136-164.

Faust, J. 1898 Beschreibung neuer Coleopteren von Vorder- und Hinterindien aus der Sammlung des Hrn. Andrewes in London. Deut. ent. Zeit., 1898(II): 273-333.

Faust, J. 1899 Viaggio di Lamberto Loria nella Papuasia orientale. XXIII. Curculionidae. Ann. Mus. Stor. Nat. Genova, XL: 5-130.

Gardner, J. C. M. 1934 Immature stages of Indian Coleoptera (14). Indian Forest Records, XX (II): $1-48$, pls.I-IV.

Günther, K. 1937 Ueber einige Curculioniden von den Salomon-Inseln. Mitt. Deut. Ent. Ges., $S(2): 37-43$.

Hartmann, F. 1900 Neue Rüsselkäfer aus Kaiser Wilhelms-Land. Deut. ent. Zschr., 1900: 273295.

Heller, K. M. 1905 Zehn neue Käfer aus Neu-Guinea. Deut. ent. Zschr., 1905: 65-76.

Heller, K. M. 1908 Neue indomalayische Rüsselkäfer. Stett. ent. Zeit., LXIX: 122-194, Taf.I.

Heller, K. M. 1929 Fauna Buruana:Curculionidae. Treubia,VII, Suppl.: 105-138, Taf. III.

Heller, K. M. 1934 New or little known Philippine Coleoptera. Philipp. J. Sci., 54: 279-307.

Heller, K. M. 1935 Neue Käfer von der Santa-Cruz- und Salomon-Inseln. Arb. morph. tax. Ent., Berlin-Dahlem, 2: 264-272, 6 figs.

Hubenthal, W. 1917 Beiträge zur Kenntnis der Curculioniden-Gattung Acicnemis Lacordaire. Arch. f. Naturg., 83 A(8): 92-169, (9): 51-155.

Hubenthal, W. 1921 Acicnemis subgen. n. Acicnemidia longimana, eine Untergattung und Art der Curculioniden Acicnemis. Arch. f.Naturg., 87 A(1O): 158-161.

Kleine, R. 1924 Neue Arten der Gattung Acicnemis Lacordaire nebst faunistischen Mitteilungen. Arch. f.Naturg., 90 A(4): 148-164.

Klima, A. 1935 Coleopterorum Catalogus, 145. Acicnemidinae. 10pp., 's-Gravenhage. 
Lacordaire, M. T. 1866 Genera des Coléoptères, VII: 1-160, Paris.

Lee, C. Y. and K. Morimoto 1988 Larvae of the weevil family Curculionidae of Japan. Part 1.

Key to genera and the short-nosed group (Insecta: Coleoptera). J. Fuc. Agr., Kyushu Univ., 33: 109-139.

Marshall, G. A. K. 1930 New Curculionidae, with notes on synonymy. Ann. Mug. nut. Hist., (10)VI: 551-577.

Marshall, G. A. K. 1931 Insects of Samoa, IV. Coleoptera, fasc. 5. Curculionidae: 249-346.

Marshall, G. A. K. 1933 Four new Indian Curculionidae (Col.). Stylops, III: 49-52.

Marshall, G. A. K. 1937 On Curculionidae from the New Hebrides. Rev. fr. Ent., 4: 39-43.

Marshall, G. A. K. 1941 New Indian Curculionidae (Col.). Ann. Mug. nut. Hist., (11)vii: 184195.

Marshall, G. A. K. 1948 Entomological results from Swedisch expedition 1934 to Burma and British India -Coleoptera: Curculionidae. Novit. Zool., 42: 397-473.

Morimoto, K. 1959 Enumerutio insectorum montis Hikosun II. Coleoptera. Curculionidae: 7887.

Morimoto, K. 1962 Descriptions of a new subfamily, new genera and species of the family Curculionidae of Japan. J. Fuc. Agr., Kyushu Univ., 11(4): 375-409.

Morimoto, K. 1962 Key to families, subfamilies, tribes and genera of the superfamily Curculionoidea of Japan excluding Scolytidae, Platypodidae and Cossoninae. J. Fuc. Agr., Kyushu Univ., 12(1): 21-66.

Morimoto, K. 1984 Curculionidae. In Hayashi, M., K. Morimoto and S. Kimoto eds., The Coleopteru of Japan in color, IV: 269-345, pls: 53-68. Hoikusha.

Morimoto, K. and S. Miyakawa 1985 Weevil fauna of the Izu Islands, Japan (Coleoptera). Mushi, 50: 19-85.

Nakane, T. 1963 New or little-known Coleoptera from Japan and its adjacent regions, XX. Curculionidae. Frugm. Col., (8-10): 31-40.

Nakane, T. 1963 Curculionidae. In Nakane et al. eds., Iconogruphiu Insectorum Juponicorum colore naturali editu, II. Coleoptera: 359-380. pls: 180-190. Hokuryukan.

Pascoe, F. P. 1872 Contributions towards a knowledge of the Curculionidae, III. J. Linn. Soc. Lond., XI: 440-492, pls. X-XIII.

Pascoe, F. P. 1885 List of the Curculionidae of the Malay Archipelago collected by Dr. Odoardo Beccari, L. M. D'Albertis, and others. Ann. Mus.. Stor. Nat. Genova, (2)11: 201 332,3 pls.

Reitter, E. 1888 Coleopteren aus Circassien, gesammelt von Hans Leder im Jahre 1887. VII. Teil. Wien. ent. Zeit., 7: 259-274.

Roelofs, W. 1875 Curculionidae recueillis au Japon par M. G. Lewis (3e). Ann. Soc. ent. Belg., XVIII: 149-193, pl.II.

Schenkling, S. and G. A. K. Marshall 1937 Coleopterorum Catalogus, 154. Trachodinae. 4pp. s'-Gravenhage.

Ter-Minasyan, M. E. 1952 Survey of long-nosed beetles of the genus Truchodes Germ. of the fauna of the USSR. Trud. zool. Inst. Akad. Nauk SSSR, 12: 317-320. (in Russian)

Thompson, R. T. 1982 The Curculionidae (Coleoptera) of Rennell Island. Natural Hist. Rennel Is., British Solomon Isls., 8: 79-120.

Thompson, R. T. 1992 Observations on the morphology and classification of weevils 
(Coleoptera, Curculionoidea) with a key to major groups. J.nat. Hist., 26: 835891.

Voss, E. 1941 Bemerkenswerte und unbeschriebene Rüsselkäfer aus China und Japan (Col., Curc.). Mitt. Münch. Ent. Ges., XXXI: 887-902.

Voss, E. 1957 Ueber einige weitere Curculioniden aus Japan (Col., Curc.).Entom. Rev. Japan, VIII: 33-39.

Voss, E. 1957 Neue und bekannte, vorwiegend Indonesische Curculioniden (Coleoptera). Treubia, 24: 7-63.

Voss, E. 1958 Ein Beitrag zur Kenntnis der Curculioniden im Grenzgebiet der orientalischen zur palaarktischen Region (Col., Curc.).Decheniana, Beihefte 5: 1-139.

Voss, E. 1958, 1960 Die von Biro auf New Guinea aufgefundenen Rüsselkäfer, II (Coleoptera Curculionidae). Ann. Hist. nut. Mus. nat. Hung., 50(s.n.IX): 209-222; id. III, 52: 315346.

Voss, E. 1962 Attelabidae, Apionidae, Curculionidae (Coleoptera Rhynchophora). Pa rc National de l'Upemba.-Misson G. F. de Witte, fasc. 44: 3-380.

Voss, E. 1971 Ueber Attelabiden und Curculioniden von den japanischen Inseln. Mem. Fac. Educ., Kagawa Univ., II(202): 43-55.

Zherichin, V. V. and A. B. Egorov 1990 Coleoptera-Curculionidae of Far East USSR. 164 pp. (Akademia Nauka, Vladivostock). (in Russian)

Zimmerman, E. C. 1967 Acicnemidinae in North America (Coleoptera:Curculionidae). Canad. Ent., 99: 1093- 1100. 


\section{Explanations of Figures}

Figs. 1-32. Photographs of

1: Trachodes subfasciatus Voss; 2: T. ovipennis n. sp.; 3: Trachodes murakamii (Morimoto); 4: T. sasajii n. sp.; 5, 6: T. monticola n. sp.; 7: T. simulator n. sp.; 8, 9: Karekizo impressicollis Morimoto; 10, 11: Acicnemis albofasciata (Ter-Minasyan); 12: A. nohirai n. sp.; 13: A. dividicincta n. sp.; 14, 15: A. dividicincta okinawana n. ssp. (14 from Okinawa I.; 15 from Amami-Oshima I.); 16: A. yakushimana n. sp.; 17: A. nobilis Hubenthal (Taiwan); 18, 19: A. palliata Pascoe; 20, 21: A. shigematsui n. sp.; 22: A. suturalis Roelofs; 23: A. dorsonigrita Voss; 24: A. kiotoensis Nakane; 25, 26: A. sauteri Hubenthal (25 from Nakanoshima I.; 26 from Taiwan); 27: A. maculaalba Roelofs; 28 : A. lueomaculata n. sp. 29: A. azumai n. sp.; 30: A. shibatai Voss; 31: A. postica Hubenthal; 32: A. exilis $\mathrm{n}$. sp.

Figs. 33-44. Trachodes subfasciatus Voss.

33: ventral surface; 34: meso- and metathoraces, lateral; 35: antenna; 36: head and rostrum; 37: metendostemite; 38: penis and spiculum gastrale; 39: apex of penis; 40: tegmen; 41: male eighth and ninth stemites; 42: antenna1 scrobes, ventral; 43: fore tarsus; 44: legs.

Figs. 45,46. Trachodes ovipennis n. sp.

45: male aedeagus; 46: legs.

Figs. 47-57. Trachodes murakamii (Morimoto).

47: ventral surface; 48: mesothorax, lateral; 49: head and rostrum; 50: antennal scrobes; 51: antenna; 52: penis; 53: eighth and ninth stemites and spiculum gastrale; 54: tegmen; 55: spermatheca; 56: fore tarsus; 57: legs.

Figs. 58-61. Trachodes sasajii n. sp.

58: penis; 59: ninth stemite and spiculum gastrale; 60: tegmen; 61: legs.

Figs. 62-63. Trachodes simulator n. $\mathrm{sp}$.

62: penis; 63: legs.

Figs. 64-71. Trachodes monticola n. sp.

64: penis; 65: basal part of penis, ventral; 66: tegmen; 67: eighth and ninth stemites and spiculum gastrale; 68: legs; 69: spermatheca; 70: antenna; 71: metendostemite.

Figs. 72-81. Karekizo impressicollis Morimoto.

72: ventral surface; 73: meso- and metathoraces, lateral; 74: head and rostrum; 75: antenna1 scrobes, ventral; 76: legs; 77: fore tarsi; 78: penis; 79: eighth and ninth sternites and spiculum gastrale; 80: tegmen; 81: spermatheca; 82: antenna.

Figs. 83-91. Acicnemis albofasciata (Ter-Minasyan).

83: penis, 84: apex of penis; 85: tegmen; 86: eighth and ninth sternites and spiculum gastrale; 87: antenna; 88: female eighth tergite and stemite; 89: apex of fore tibia showing uncus; 90: tentorium, dorsal and lateral; 91: legs.

Figs. 92-97. Acicnemis nohirai n. sp.

92: apical segments of antenna; 93: penis, 94: tegmen; 95: apex of ovipositor; 96: spermatheca; 97: legs.

Figs. 98-103. Acicnemis dividicincta dividicincta n. sp. 
98: penis, 99: tegmen; 100, 101: spermatheca; 102: apical segments of antenna; 103: legs.

Figs. 104-107. Acicnemis dividicincta okinawana n. ssp.

104: spermatheca; 105: penis; 106: apical segments of antenna; 107: legs.

Figs. 108-1 11. Acicnemis yakushimana $\mathrm{n}$. sp.

108: penis; 109: spermatheca; 110: legs, 111: apical segments of antenna.

Figs. 112-1 14. Acicnemis palliata Pascoe.

112: penis; 113: spermatheca; 114: legs.

Fig. 115. Acicnemis shigemutsui n. sp., legs.

Figs. 116-121. Acicnemis suturalis Roelofs.

116: male aedeagus; 117: spermatheca; 118: legs (female); 119-121: apex of tibiae (male).

Figs. 122-125. Acicnemis dorsonigrita Voss.

122: male aedeagus, 123: apical segments of antenna; 124: spermatheca; 125: legs.

Figs. 126-127. Acicnemis sauteri Hubenthal.

126: apical segments of antenna; 127: legs.

Figs. 128-134. Acicnemis kiotoensis Nakane.

128: penis; 129:ap£xpenis; 130: tegmen; 131: eighth and ninth sternites and spiculum gastrale; 132: spermatheca; 133: ovipositor and bulsa copulatrix showing a lobe at junction of oviduct, spermathecal duct and bulsa copulatrix; 134: legs.

Figs. 135-140. Acicnemis maculaalba Roelofs.

135: male aedeagus; 136apex penis; 137: tegmen; 138: spermatheca; 139: legs; 140: apical segments of antenna.

Figs. 141-146. Acicnemis luteomaculata $\mathrm{n}$. sp.

141: penis; 142: eighth and ninth sternites and spiculum gastrale; 143: tegmen; 144: spermatheca; 145: legs, 146: apical segments of antenna.

Figs. 147-151. Acicnemis azumai $\mathrm{n}$. sp.

147: male aedeagus; 148: antenna1 funicle and club; 149: spermatheca; 150: ninth sternite (male); 151: legs.

Figs, 152-156. Acicnemis shibutui Voss.

152: male aedeagus; 153: legs, 154: tegmen; 155: spermatheca; 156: antenna.

Figs. 157-162. Acicnemis posticu Hubenthal.

157: male aedeagus; 158: eighth and ninth sternites; 159: tegmen; 160: spermatheca; 161:

legs; 162: apical segments of antenna.

Figs. 163-167. Acicnemis exilis $\mathrm{n}$. sp.

163: penis; 164: ninth sternite and spiculum gastrale; 165: legs; 166: spermatheca; 167: apical segments of antenna. 


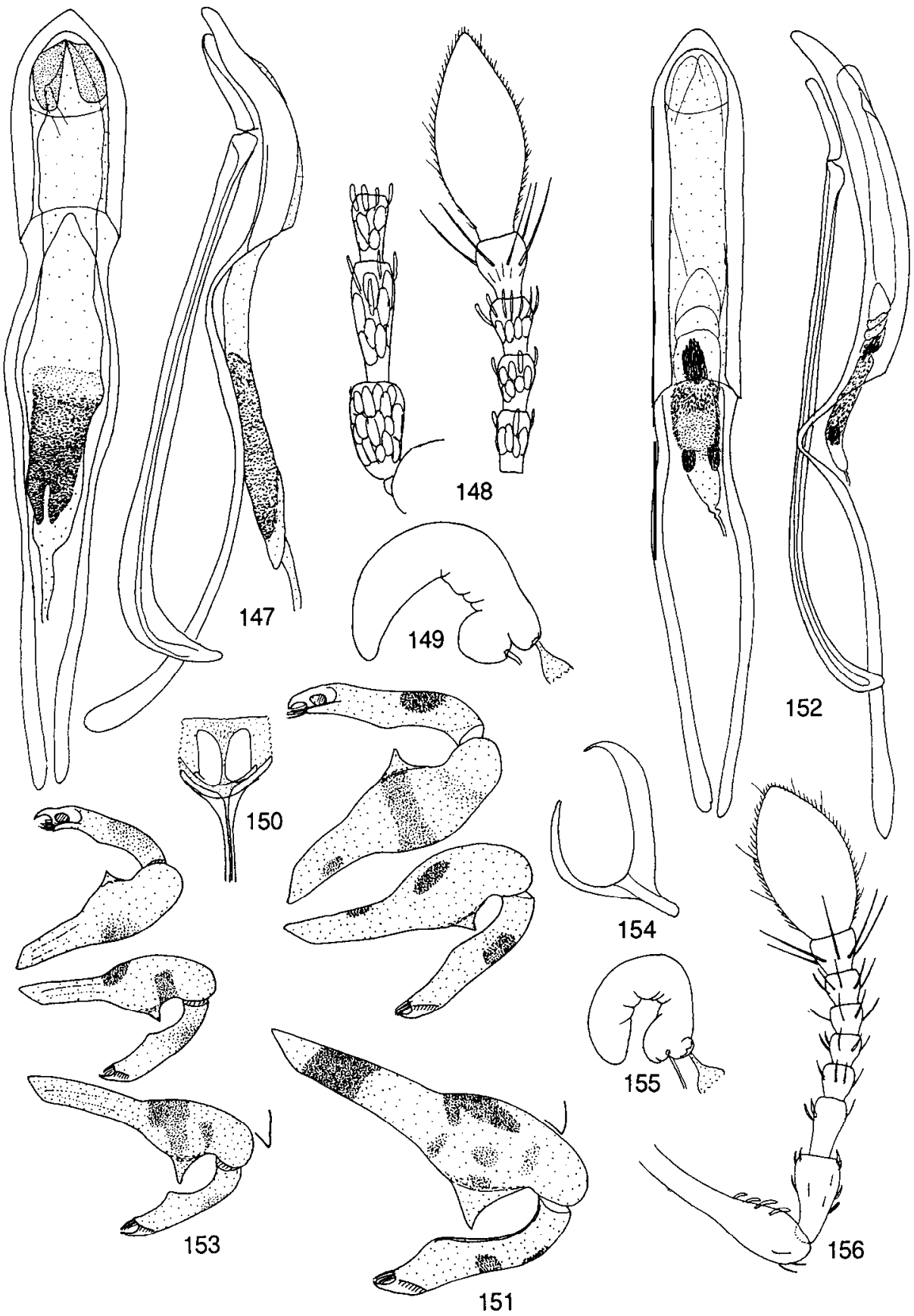




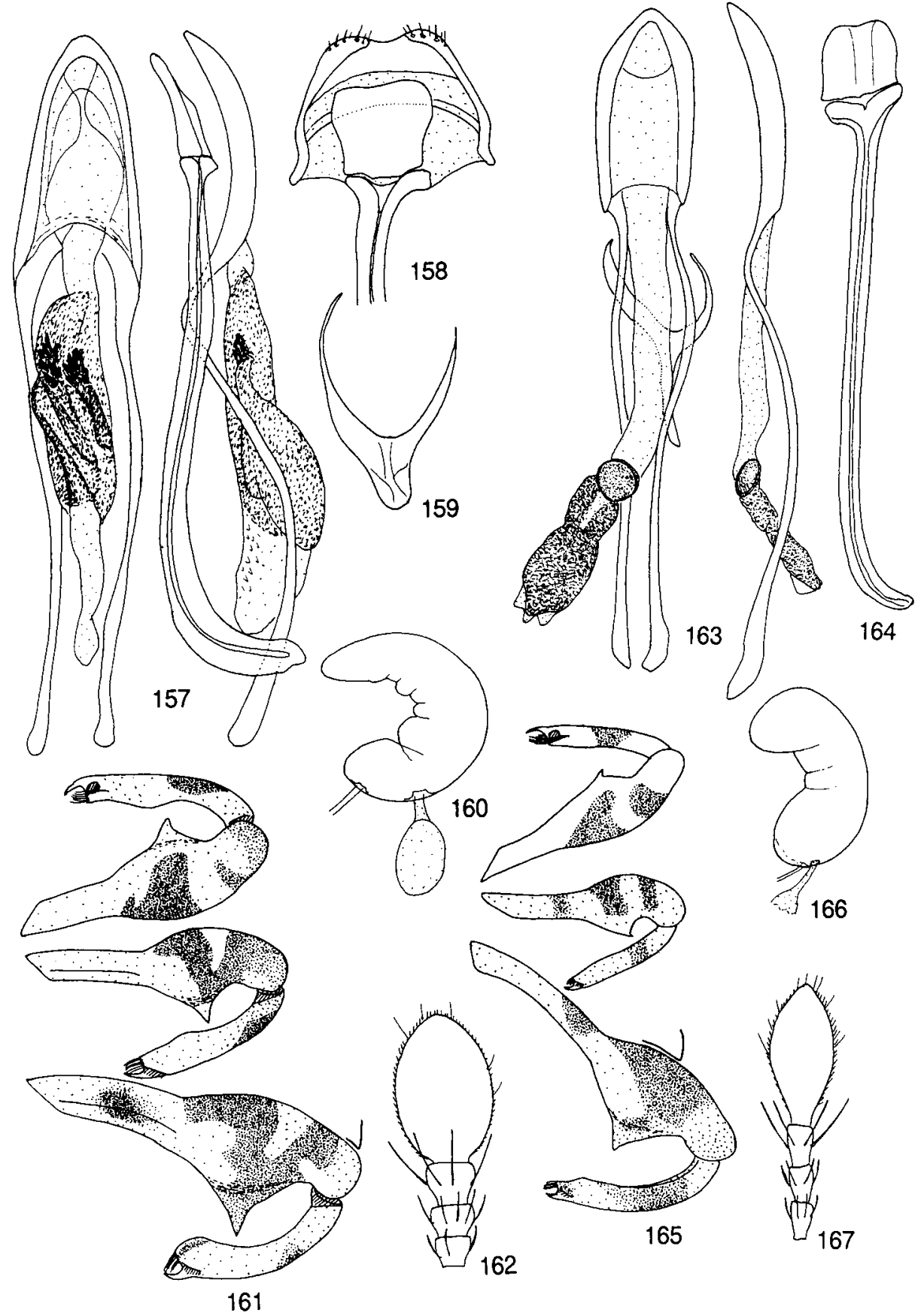



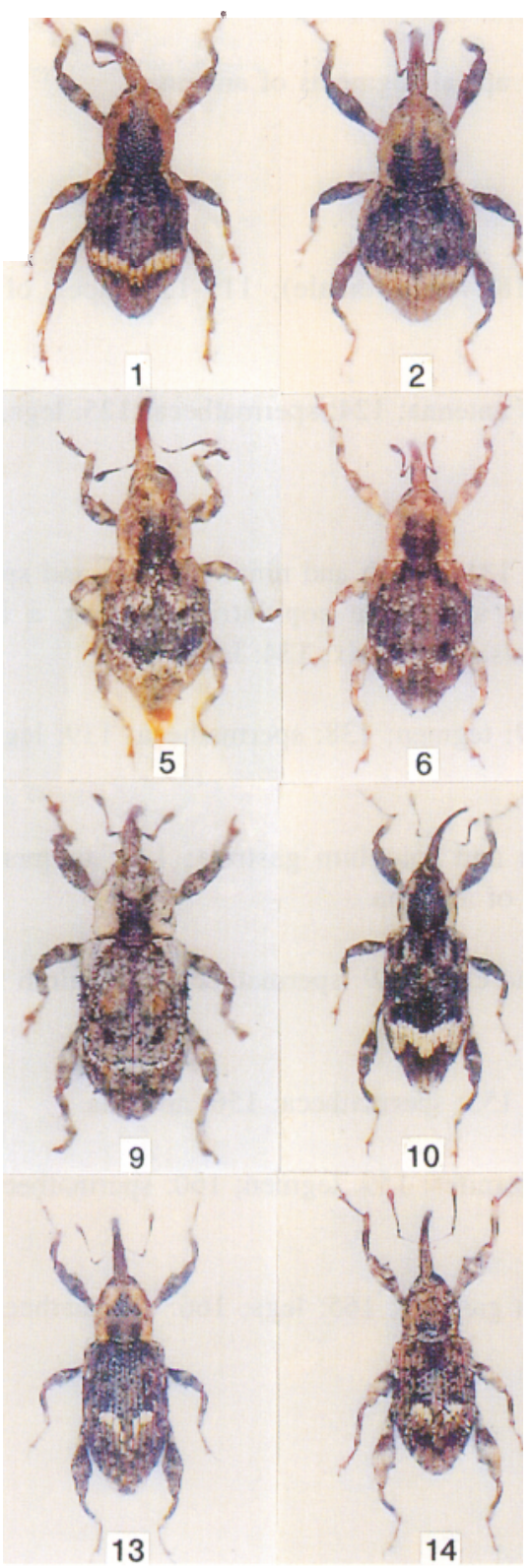
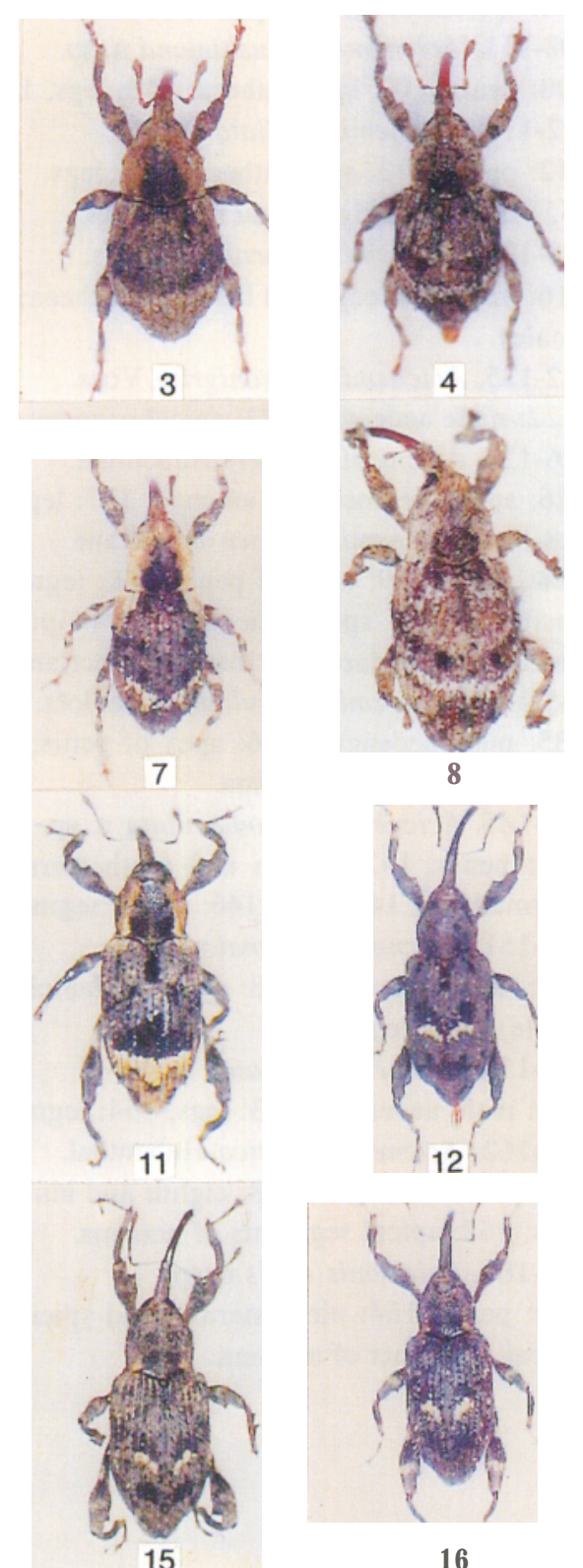

16 


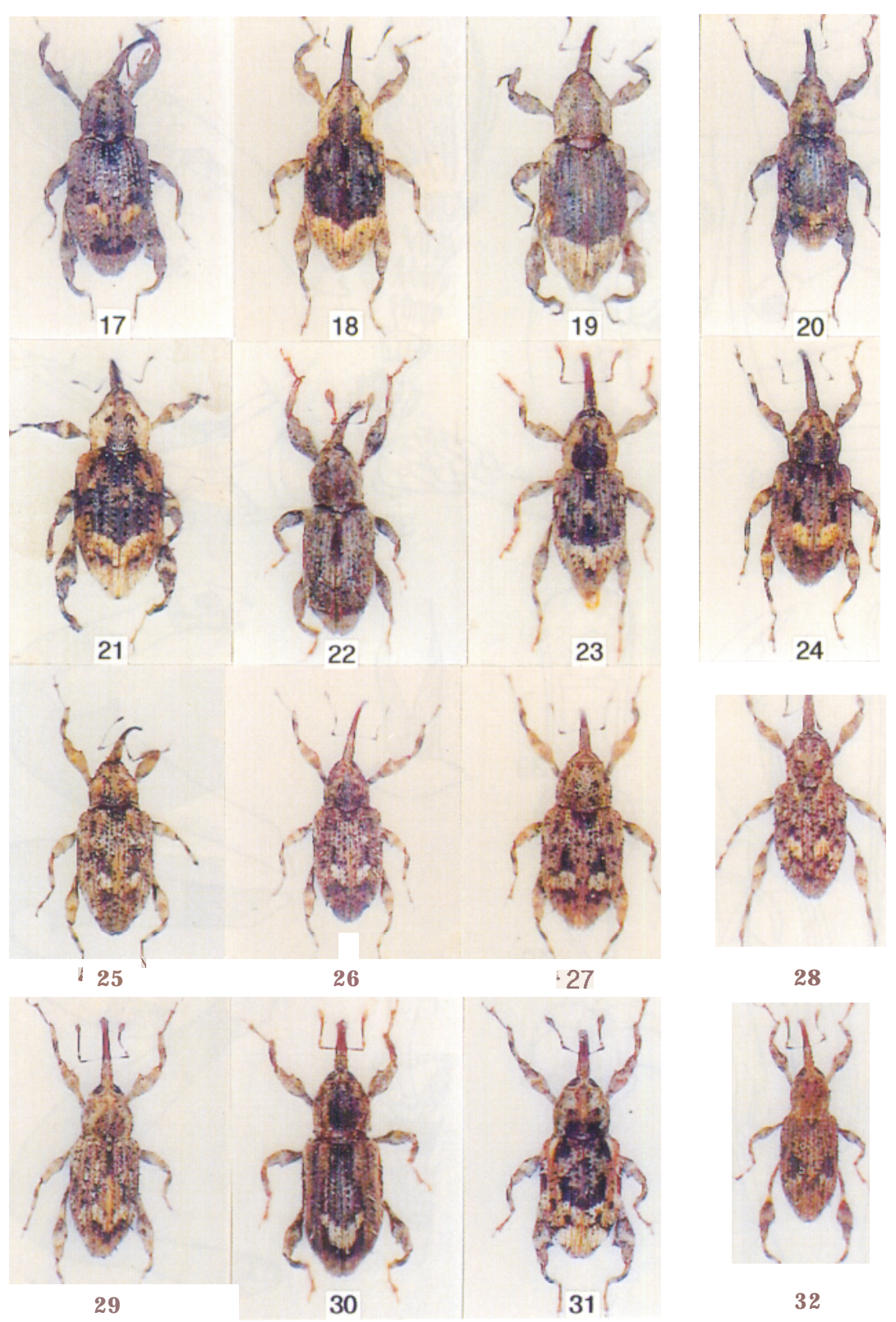



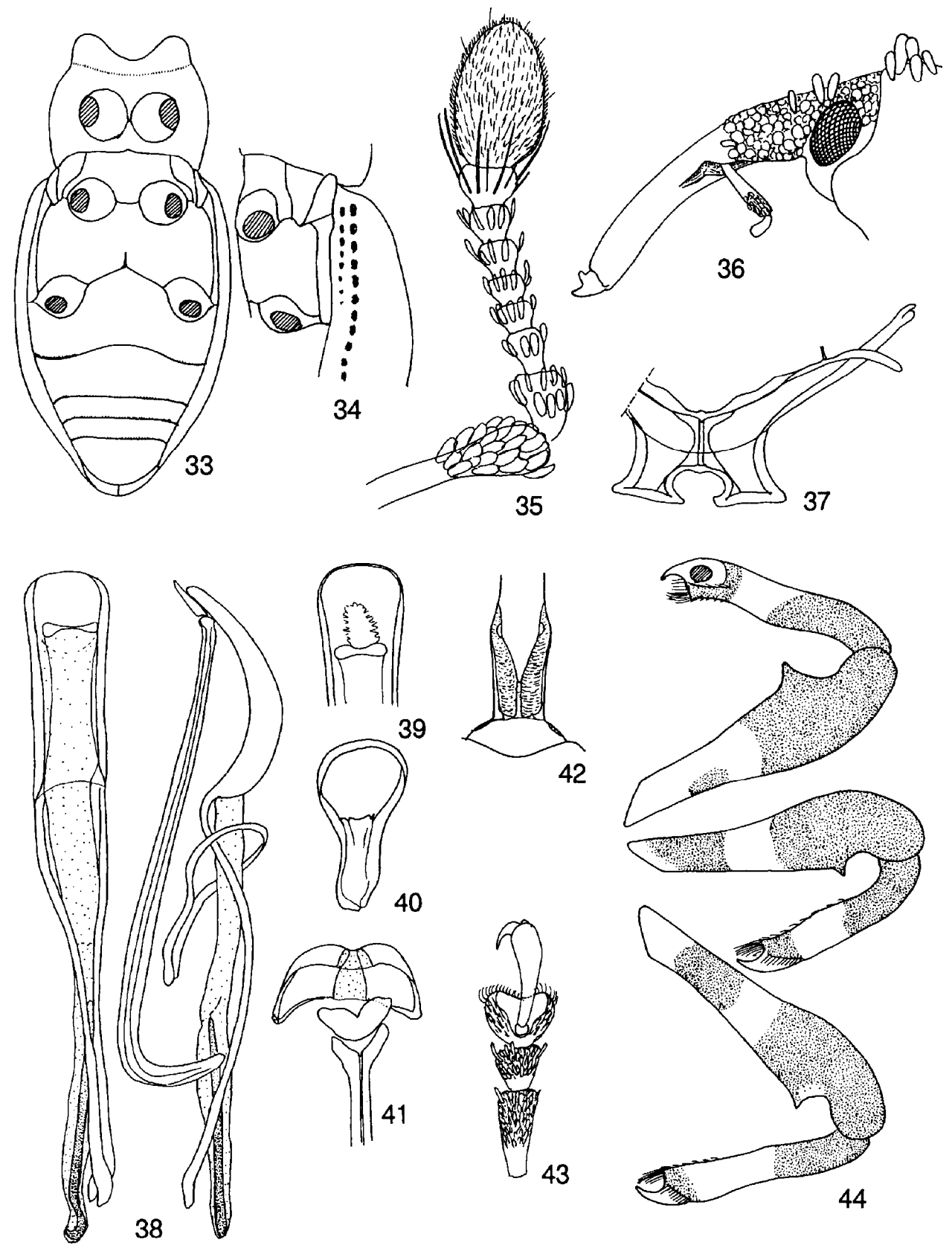

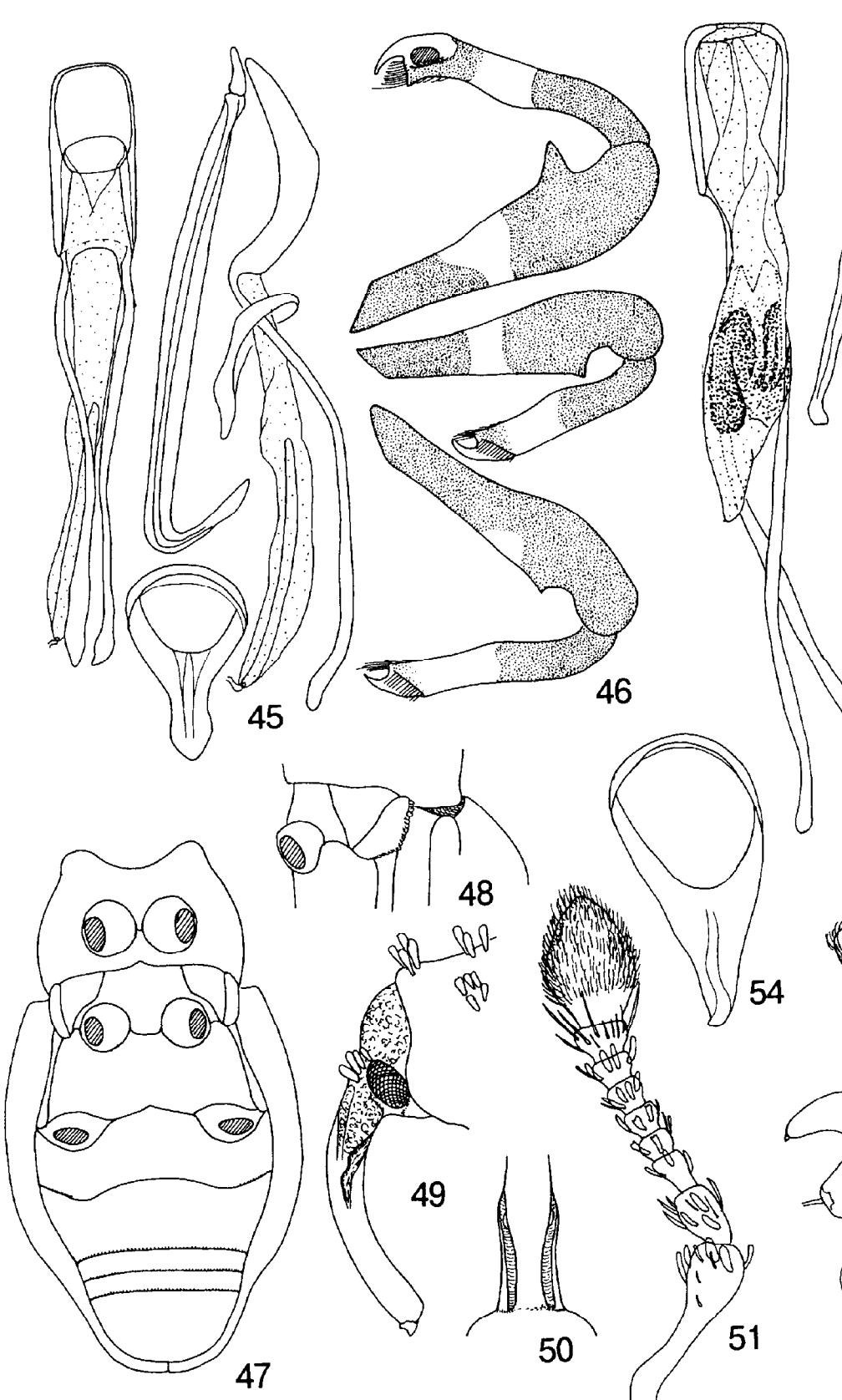


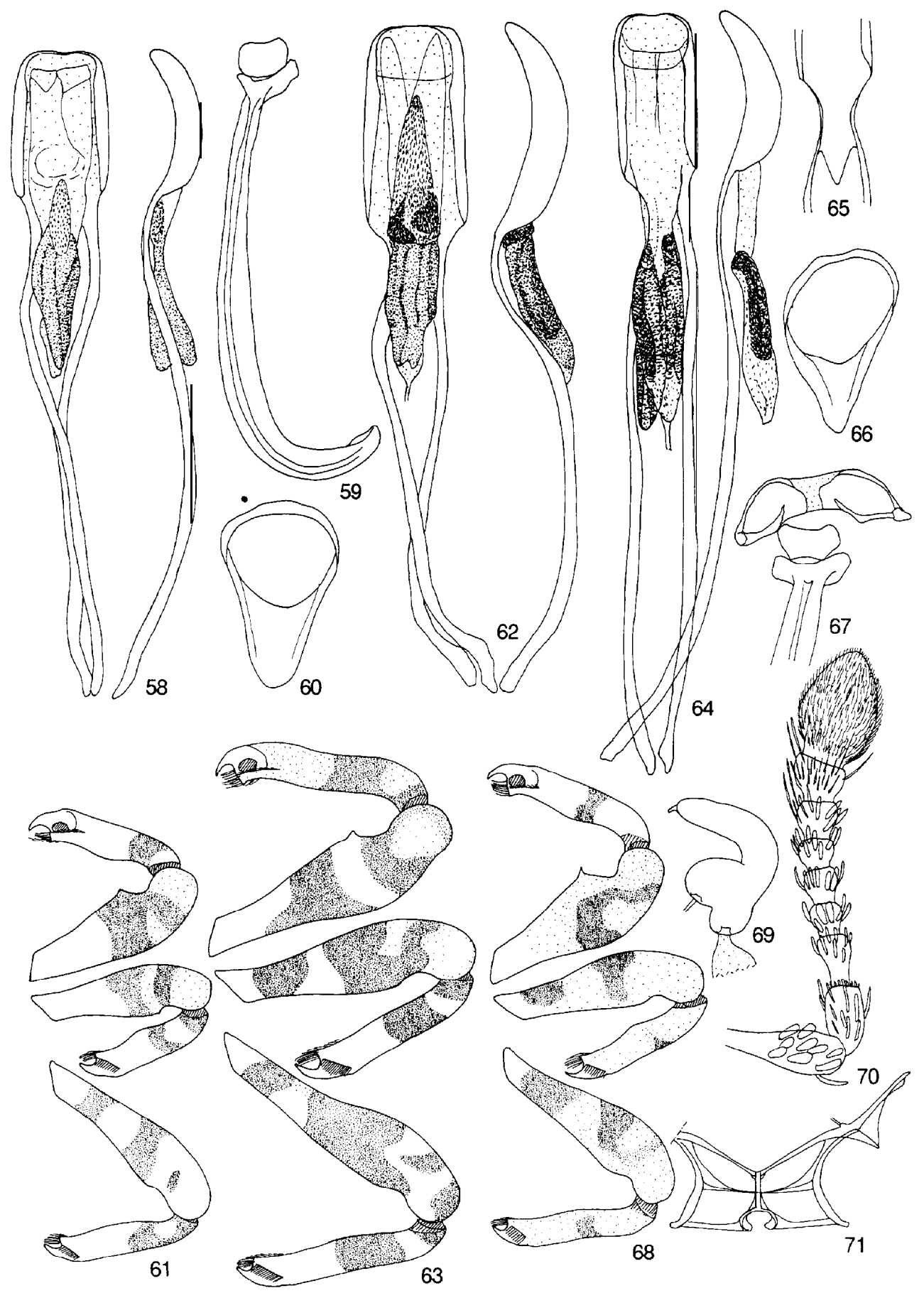




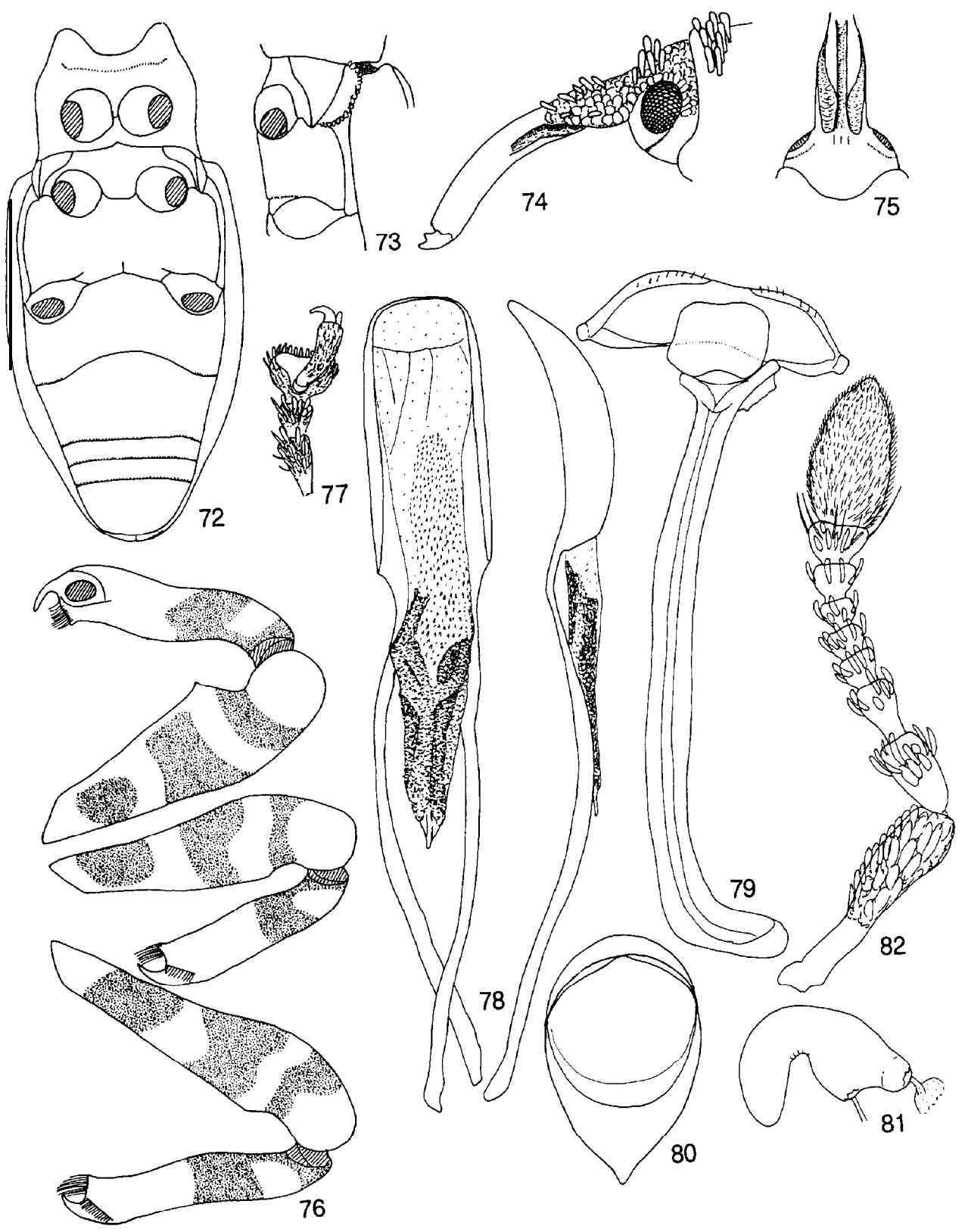


K. MORIMOTO \& S. MIYAKAWA

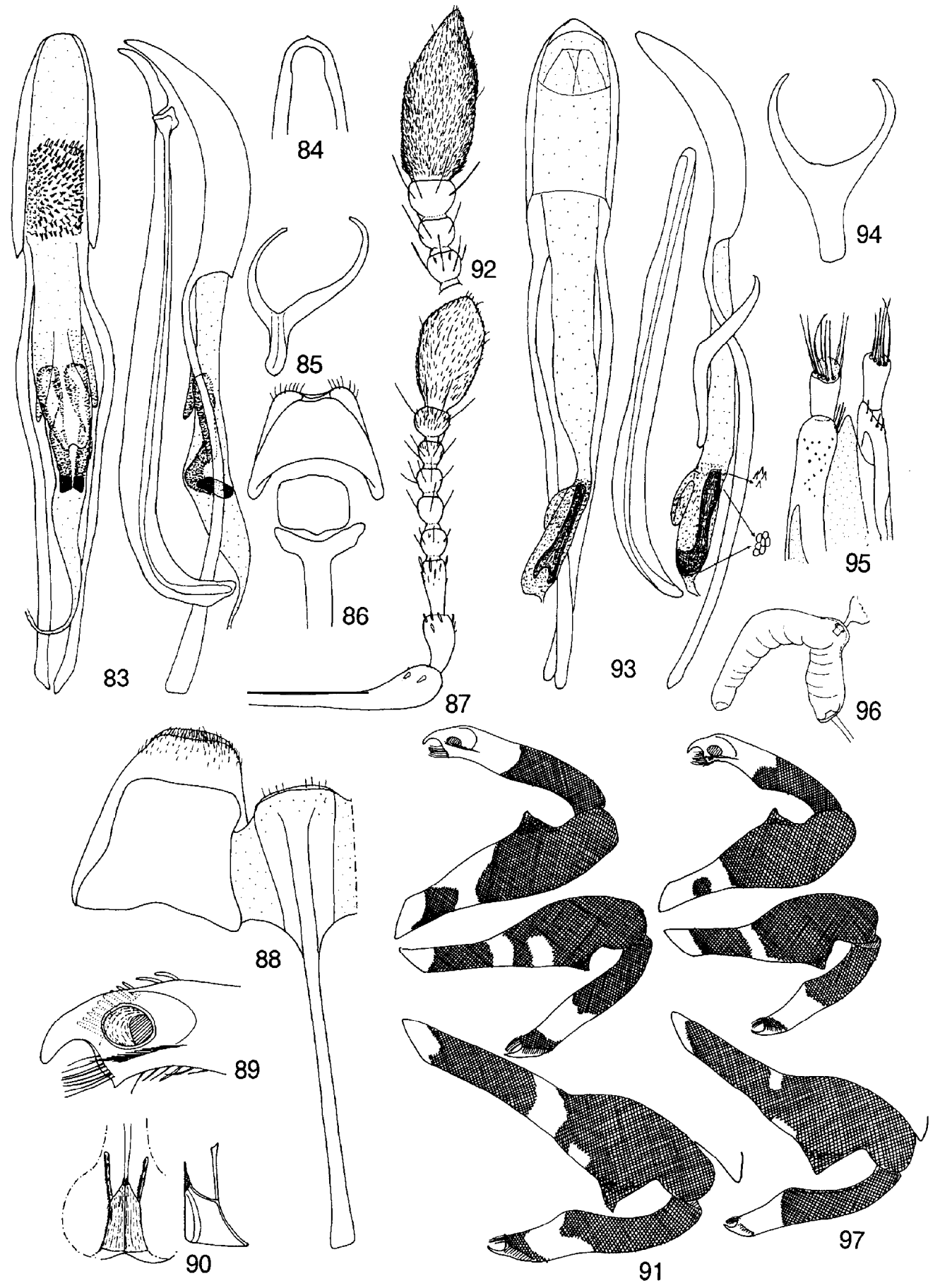




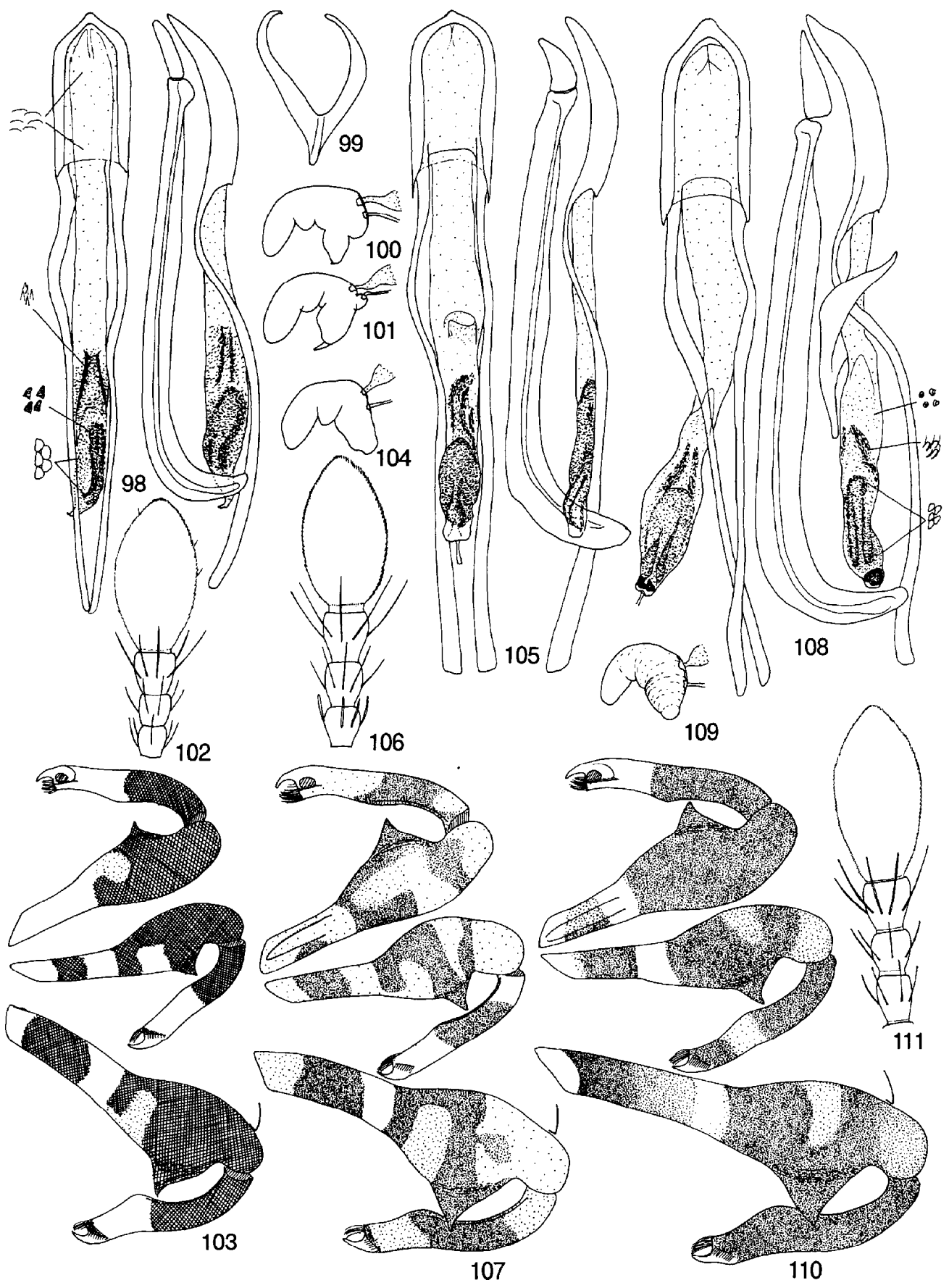




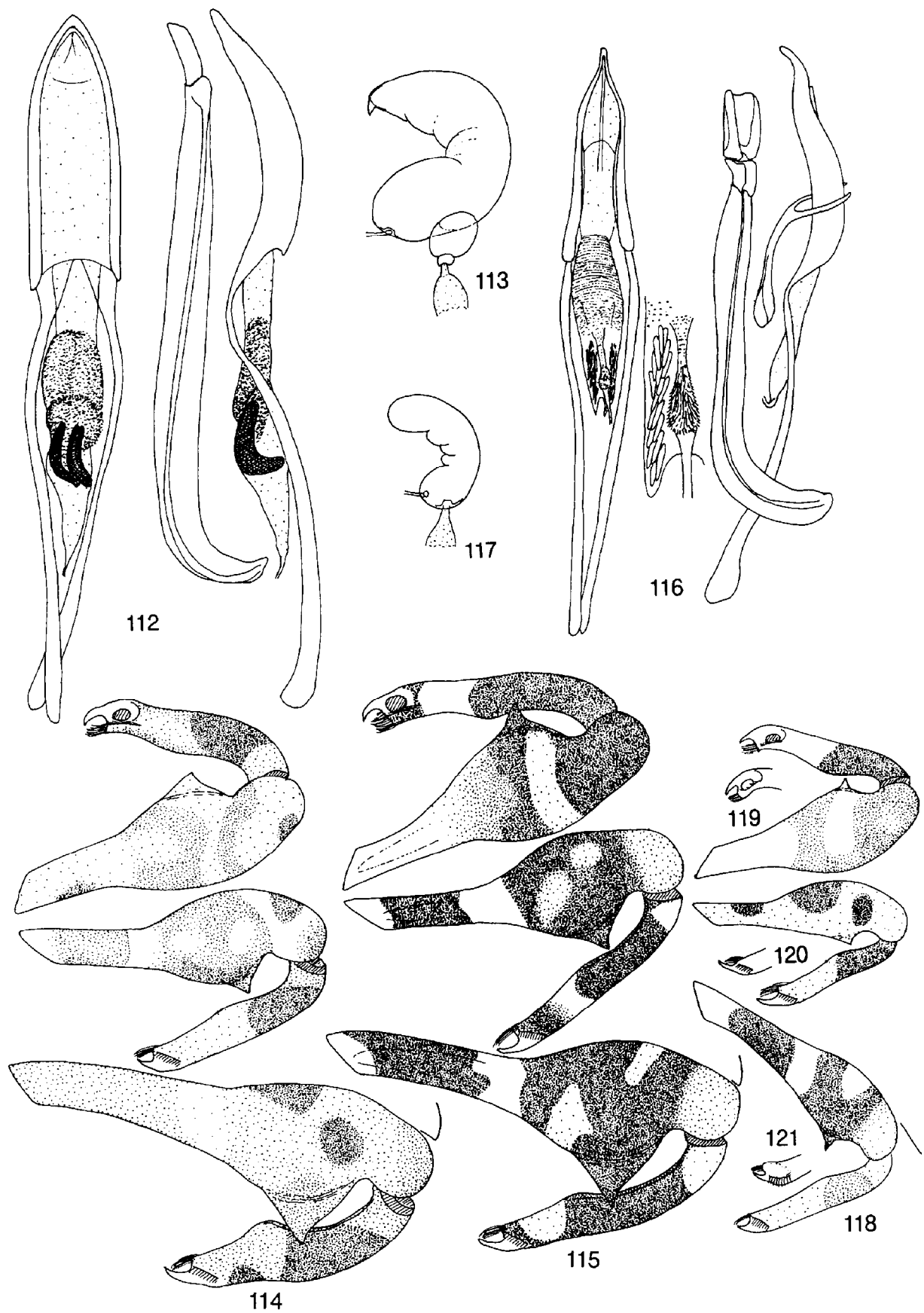




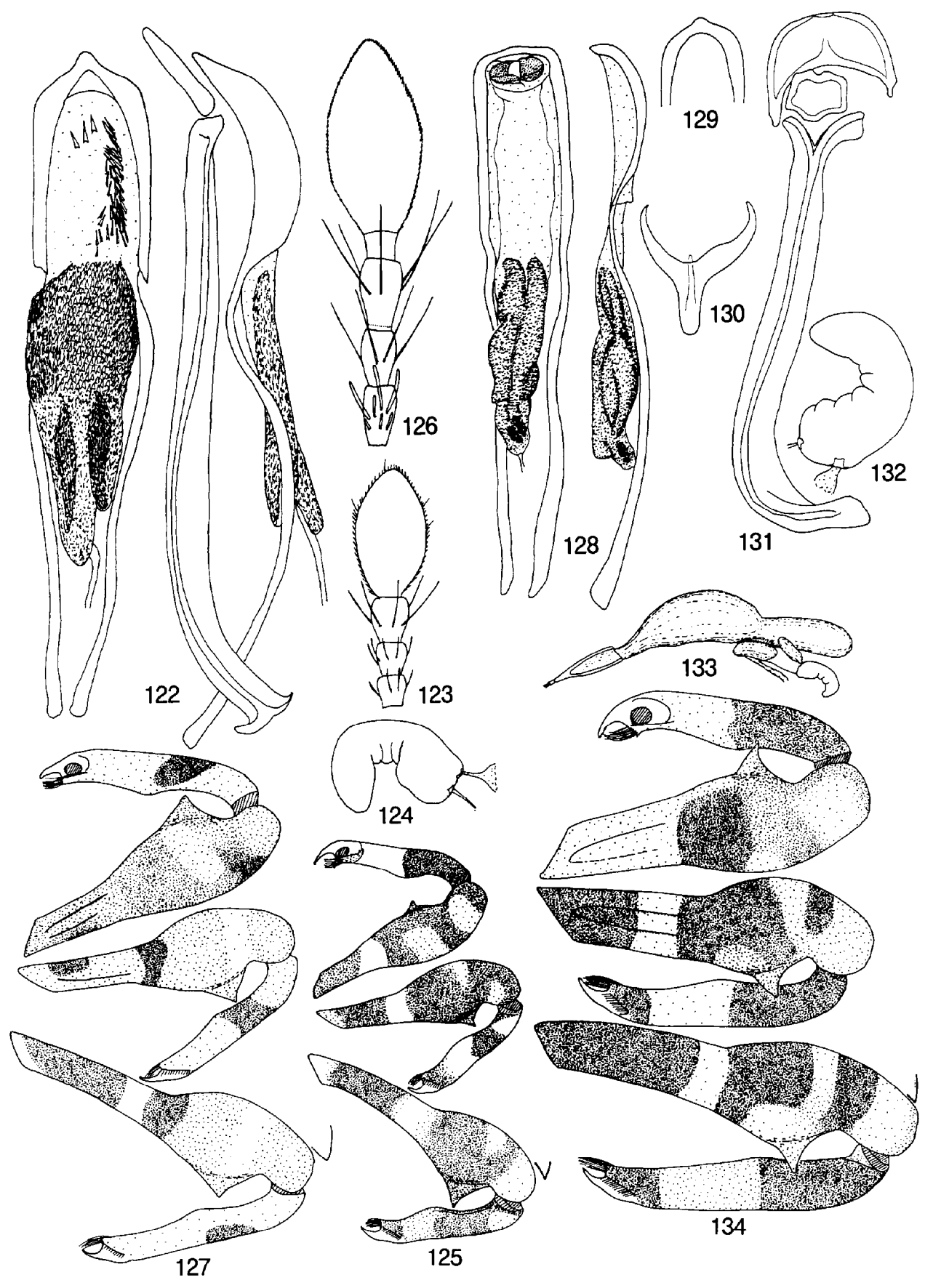


K. MORIMOTO \& $\mathbf{S}$. MIYAKAWA

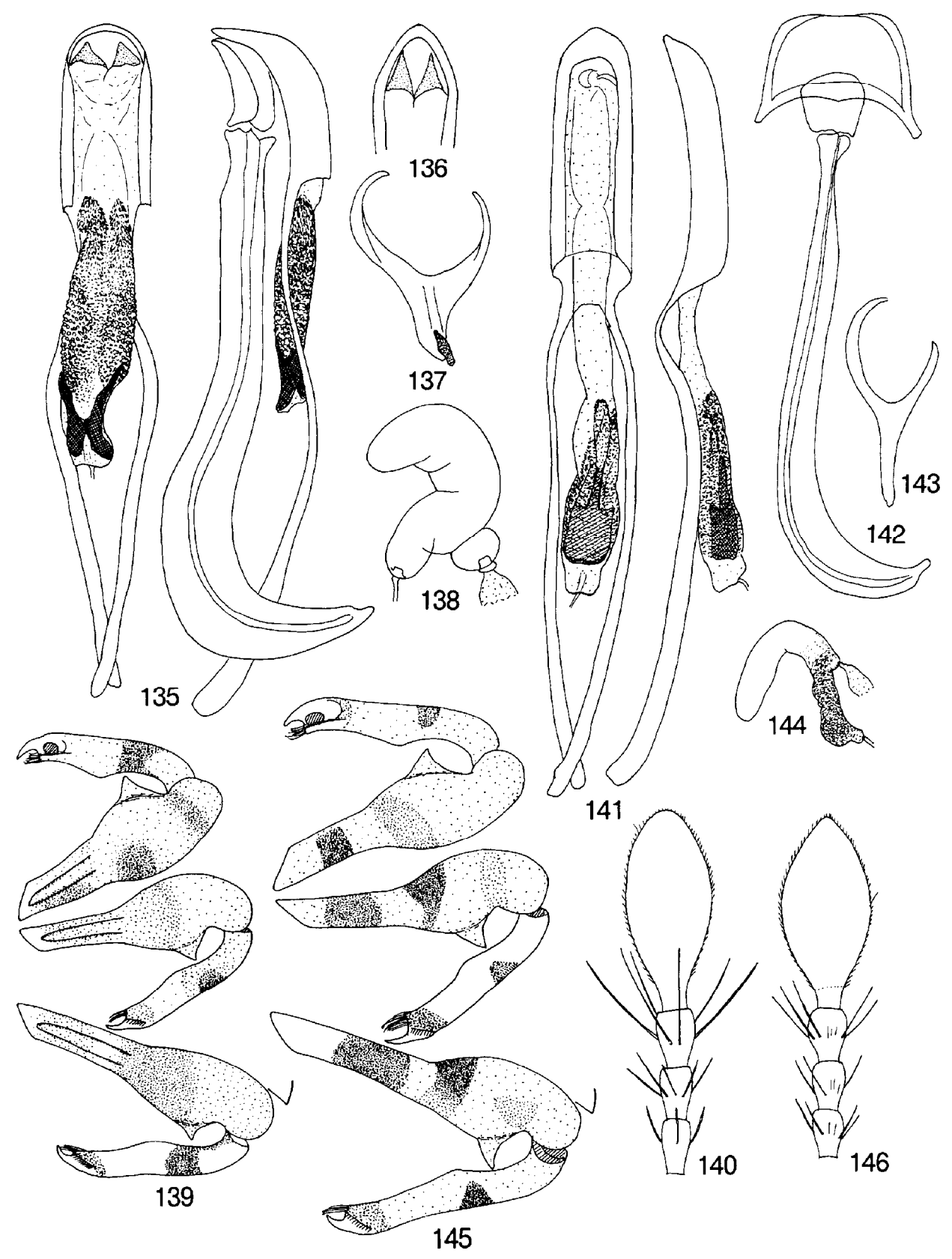




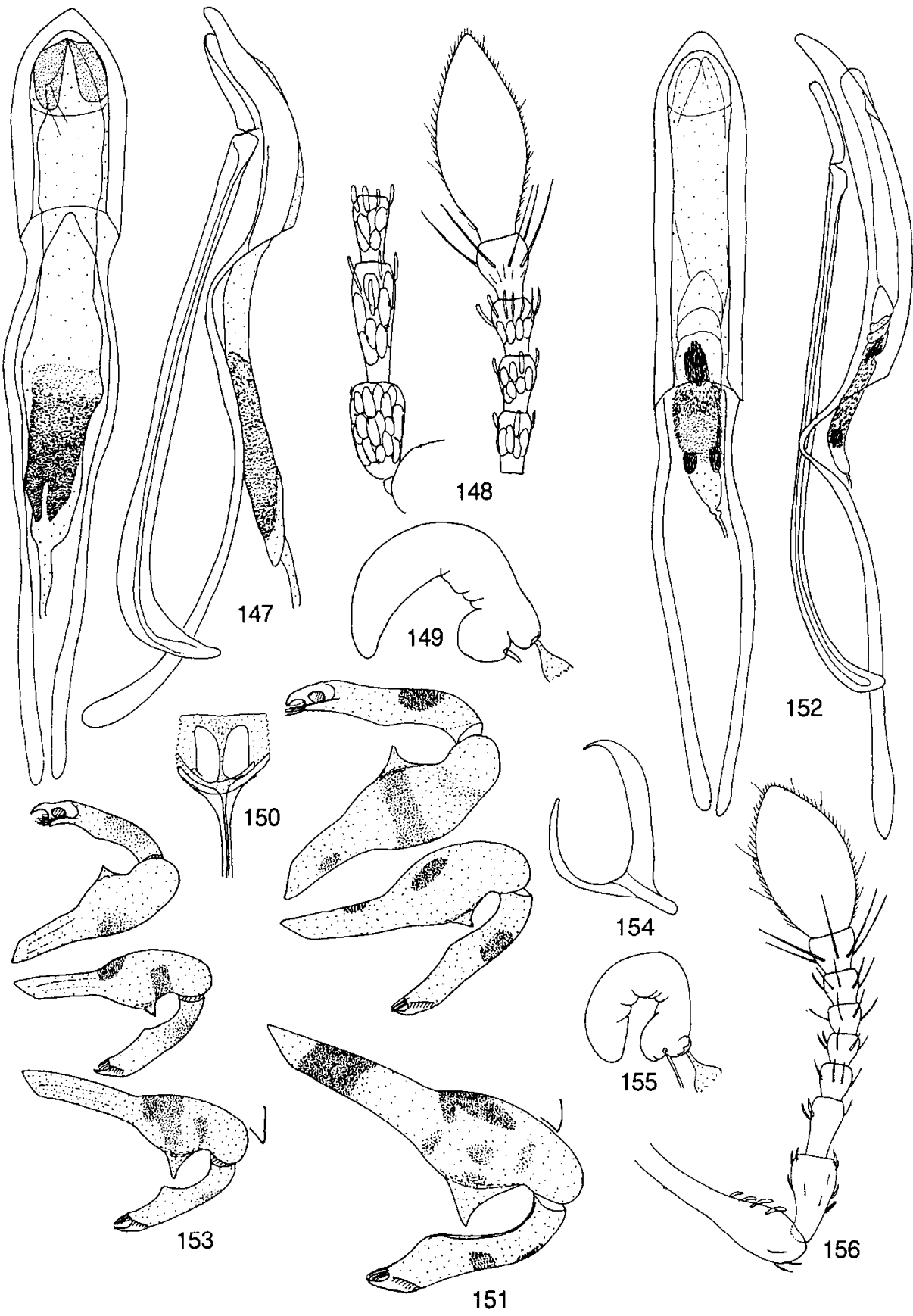




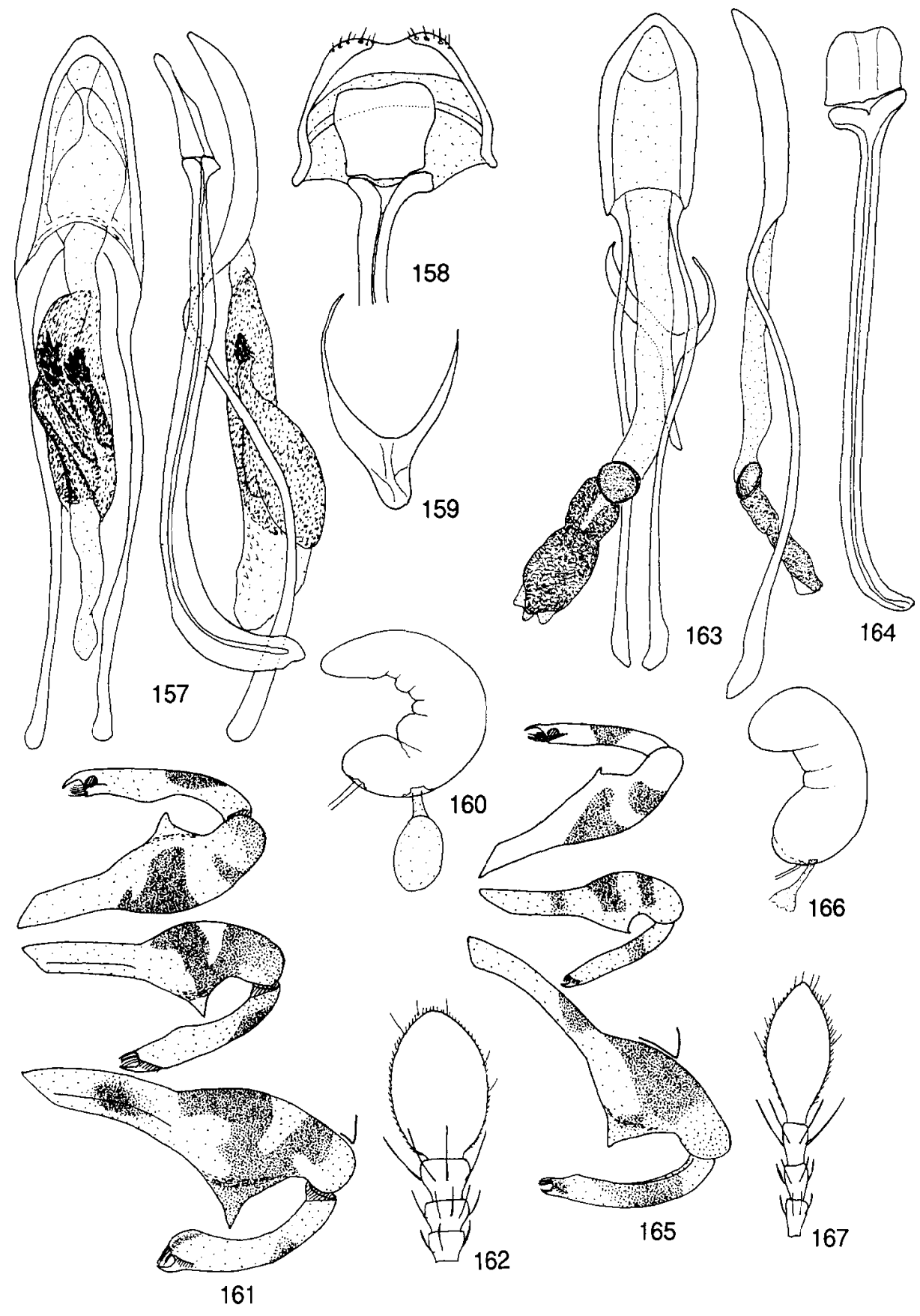

